46

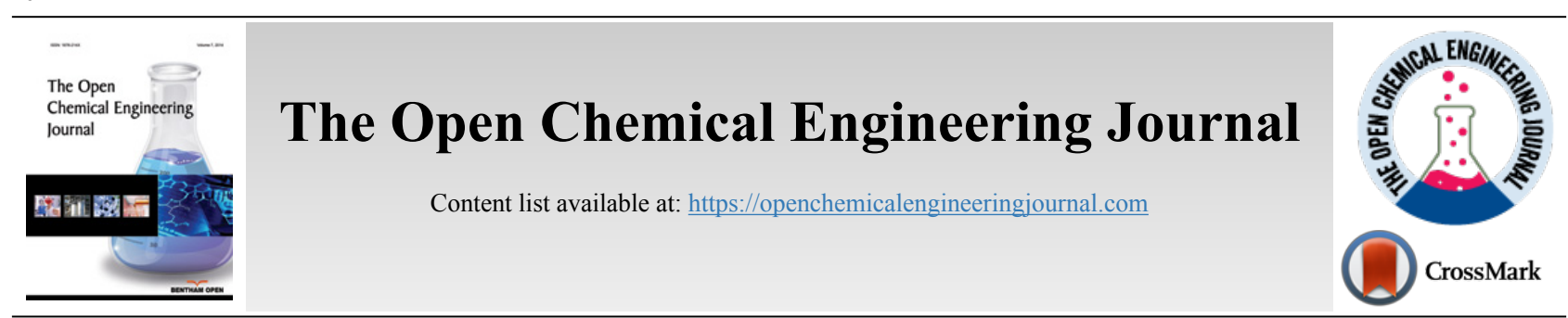

RESEARCH ARTICLE

\title{
Industrial Manufacturing of Aqueous Solutions of Sodium Sulfhydrate (NaHS $43 \%$ ) in a Multi-Phase Reactor
}

\author{
Warren Reátegui-Romero ${ }^{1, *}$, Fredy Castillejo-Melgarejo ${ }^{1,2}$ and María E. King-Santos ${ }^{1}$ \\ ${ }^{1}$ Faculty of Chemical Engineering and Textile(FIQT)- Universidad Nacional de Ingeniería (UNI), Lima Peru \\ ${ }^{2}$ Reactivos Nacionales S.A. Company, Lima Peru
}

\begin{abstract}
:
Background:

This research deals with the manufacture of sodium sulphides and sodium sulfhydrate in an isothermal multiphase chemical reactor to produce concentrated aqueous solutions of sodium sulfhydrate (greater than 43\%) through Gas-Liquid-Solid reactions from hydrogen sulfide and hydroxide of sodium at $50 \%$.

Methods:

A method is proposed that integrates the recovery of hydrogen sulfide from an industrial chemical process where the $\mathrm{H}_{2} \mathrm{~S}$ gas is generated as a sub product, the strategy of the developed process was integrated into a manufacturing plant of dithiophosphoric acids (ADTF) where it was possible to recover the hydrogen sulfide in the form of an aqueous solution of NaHS with a concentration higher than $43 \%$.

Results:

The experimental tests showed that the biphasic reaction mixture formed by $\mathrm{Na}_{2} \mathrm{~S}, \mathrm{NaHS}$ and $\mathrm{H}_{2} \mathrm{O}$ with global compositions of $13.3 \%$; $26.9 \%$ and $59.7 \%$ respectively, is appropriate to obtain $43 \%$ sodium sulfhydrate in a stirred tank reactor, operated at temperatures ranging from $50^{\circ} \mathrm{C}$ to $55^{\circ} \mathrm{C}$, where gaseous hydrogen sulfide is continually bubbled.

Conclusion:

Sodium sulfide (specifically $\mathrm{Na}_{2} \mathrm{~S} .5 \mathrm{H}_{2} \mathrm{O}$ crystals) of the biphasic mixture is produced from a solution of sodium sulfhydrate (43\% NaHS) and aqueous sodium hydroxide $(50 \% \mathrm{NaOH})$. The environmental problem generated by the $\mathrm{H}_{2} \mathrm{~S}$ was solved with a $90 \%$ recovery in the multiphase reactor and $5 \%$ in the safety absorber.
\end{abstract}

Keyword: Sodium hydrosulphide (NaHS), Multiphasic reactors, Sodium sulphide and Hydrogen sulfide( $\left.\mathrm{H}_{2} \mathrm{~S}\right)$, Reactivos Nacionales S.A.

\begin{tabular}{|l|l|l|l}
\hline Article History & Received: December 04, 2018 & Revised: April 13, 2019 & Accepted: April 18, 2019
\end{tabular}

\section{INTRODUCTION}

Hydrogen sulfide is a highly toxic gas [1, 2, 3]; with an offensive odour reminiscent of rotten eggs $[4,5]$ it is readily water soluble [3]. One of the problems caused by hydrogen sulfide with respect to the health and safety of personnel is the time and concentration of exposure. If exposed to $100 \mathrm{ppm} \mathrm{H}_{2} \mathrm{~S}$ during 8 hours, people will hemorrhage and die. Concentrations above $600 \mathrm{ppm}$ can be fatal if exposed between 3 and 5 minutes [6]. Exposure to $\mathrm{H}_{2} \mathrm{~S}$ is highly dangerous and the sequelae that can appear in people who survive acute pois-

\footnotetext{
* Address correspondence to this author at the Faculty of Chemical Engineering and Textile(FIQT)- Universidad Nacional de Ingeniería (UNI), Lima Peru;

E-mail:wreategui@uni.edu.pe
}

oning are generally neurological post-anoxic. Chronic exposure can cause chronic bronchitis and neuro-psychic symptoms [7]. Industrial emissions that contain low concentrations of hydrogen sulfide (less than $1 \mathrm{ppm}$ ) have odor problems [8] that affect the environment, and exposure to high concentrations (greater than $100 \mathrm{ppm}$ ) has effects on people's health leading to fatal consequences, see www.osha.gov [9]. Chemical industries - especially those industries that generate high concentrations and volumes that affect the economy of the main process - are constantly searching for chemical control methods of these emissions and their final disposal. A method of chemical control of hydrogen sulfide gas consists of transforming it into stable substances with commercial value such as elemental sulfur $[10,11]$ or using processes that transform H2S without 
production of inorganic salt byproducts and wastewater [12] and stable aqueous solutions of sodium sulphide and sodium sulfhydrate and other salts $[13,14]$. In the oil and gas industry there are advanced treatment of acid gases $\left(\mathrm{H}_{2} \mathrm{~S}\right)$ where seven ways to remove $\mathrm{H}_{2} \mathrm{~S}$ from crude oil and gas are described [15]. Absorption is used in the oil \& gas industry to remove $\mathrm{H}_{2} \mathrm{~S}$ and carbon dioxide from sour natural gas and refinery gas. This removal is called gas sweetening, which consists in the transfer of $\mathrm{H}_{2} \mathrm{~S}$ from the gas phase to the liquid phase [16]. Caustic scrubbing is a technology that has been used for the removal of $\mathrm{H}_{2} \mathrm{~S}$ from gases in variety of industries for many years. According to McIntosh, et al., 2012 improvement in design and controls strategies, favorable prices for caustic compared with other non-regenerable $\mathrm{H}_{2} \mathrm{~S}$ scavenging chemicals, and the potential for sales value for the NaHS product have made caustic scrubbing an economic and viable option for many refinery streams [17]. Industrially the manufacture of the sulfhydrate of aqueous sodium is made by the chemical reaction of a solution of sodium hydroxide and hydrogen sulfide according to the following reaction [18].

$$
\mathrm{H}_{2} \mathrm{~S}+\mathrm{NaOH} \leftrightarrow \mathrm{NaHS}+\mathrm{H}_{2} \mathrm{O} .
$$

The chemical reaction is carried out in absorption towers (filling columns) that operate countercurrent and at temperatures around $70{ }^{\circ} \mathrm{C}$, preferably at $90{ }^{\circ} \mathrm{C}$. The manufacturing processes of sodium sulfhydrate are differentiated by the source of hydrogen sulfide [19]: Fosfoquim process when the $\mathrm{H}_{2} \mathrm{~S}$ coming from the reaction of $\mathrm{H}_{2}$ and Sulfur, Akzo Nobel process if the $\mathrm{H}_{2} \mathrm{~S}$ coming from the manufacture of $\mathrm{CS}_{2}$ and Tessenderlo Kerley if $\mathrm{H}_{2} \mathrm{~S}$ coming from the desulfurization of Natural Gas or Oil. These processes have the advantage of producing sodium sulfhydrate continuously and for this the process is provided with a series of auxiliary absorbers that allow to neutralize the $\mathrm{H}_{2} \mathrm{~S}$ that has not been absorbed in the main absorber due to its low solubility in the absorbent solution. These processes require working at temperatures close to $100^{\circ} \mathrm{C}$ to avoid the crystallization of sodium sulphide inside the packing of the packed column and at the bottom of the tower [19]. In packed towers, the absorbent liquid may be aqueous sodium hydroxide or a pre-warmed sodium sulfide solution to avoid crystallization of sodium sulphides in the transfer lines [20]. Some absorbers are provided with stirred tanks in their lower part where it allows to prepare the sodium sulfide that will be recirculated in the absorption tower. The reactions in the process are exothermic (Eq. 9) [21], so the heat generated must be removed by means of water-cooled heat exchangers and by water jackets that are installed in the recirculation tank and in the absorption towers themselves.

Formation of sodium sulfide crystals from $\mathrm{NaOH}$ :

$$
\begin{aligned}
& \mathrm{NaOH}(\mathrm{aq})+\mathrm{NaHS}(\mathrm{aq}) \rightarrow \mathrm{Na}_{2} \mathrm{~S}(\mathrm{aq})+\mathrm{H}_{2} \mathrm{O}(\mathrm{l}) \\
& \mathrm{Na}_{2} \mathrm{~S}(\mathrm{aq})+5 \mathrm{H}_{2} \mathrm{O}(\mathrm{l}) \stackrel{T>50^{\circ} \mathrm{C}}{\longleftrightarrow} \mathrm{Na}_{2} \mathrm{~S} .5 \mathrm{H}_{2} \mathrm{O}(\mathrm{s})
\end{aligned}
$$

Formation of sulfhydrate from sodium sulfide.

$$
\begin{gathered}
N a_{2} \mathrm{~S} .5 \mathrm{H}_{2} \mathrm{O}(\mathrm{s}) \leftrightarrow \mathrm{Na}_{2} \mathrm{~S}(\mathrm{aq}) \mathrm{Na} 2 \mathrm{~S}+5 \mathrm{H}_{2} \mathrm{O}(\mathrm{l}) \\
N a_{2} \mathrm{~S}(a q)+H_{2} \mathrm{~S}(\mathrm{~g}) \stackrel{T<50^{\circ} \mathrm{C} \text { to } 55^{\circ} \mathrm{C}>}{\longrightarrow} 2 \mathrm{NaHS}(a q)
\end{gathered}
$$

The industrial production of dithiophosphoric acids (ADTF) at Reactivos Nacionales S.A generates significant amounts of hydrogen sulfide (Eq 6), as an undesirable byproduct has a high treatment cost, and its final disposal in aqueous solutions of $20 \% \mathrm{Na}_{2} \mathrm{~S}$ affects the economy of the process principal.of reactor established to maintain

$$
\mathrm{P}_{4} \mathrm{~S}_{10}(\mathrm{~s})+8 \mathrm{R}-\mathrm{OH}(\mathrm{l}) \rightarrow 4 \text { (R-O) } 2(\mathrm{PS})-\mathrm{SH}(\mathrm{l})+\mathrm{H}_{2} \mathrm{~S}(\mathrm{~g})
$$

Where R-OH represents an alcohol typically isopropanol, isobutanol or isopentanol, and $\mathrm{P}_{4} \mathrm{~S}_{10}$ (s) at phosphorus pentasulfide. The process of NaHS production in a multiphase reactor can be explained with the chemical Eqs. (7-9) whose heats of reaction are $-4.51,-3.64$ and $-8.15 \mathrm{Kcal} / \mathrm{mol}$ respectively [22].

Stage 1:

$$
\mathrm{NaOH}(\mathrm{aq})+\mathrm{NaHS}(\mathrm{aq}) \leftrightarrow \mathrm{Na}_{2} \mathrm{~S}(\mathrm{aq})+\mathrm{H}_{2} \mathrm{O}(\mathrm{l})
$$

Stage 2:

$$
\mathrm{H}_{2} \mathrm{~S}(\mathrm{aq})+\mathrm{Na}_{2} \mathrm{~S}(\mathrm{aq}) \leftrightarrow 2 \mathrm{NaHS}(\mathrm{aq})
$$

Global process:

In the scrubbing process, $\mathrm{NaOH}$ react with $\mathrm{H}_{2} \mathrm{~S}$ dissolved in aqueous solution to form NaHS or Sodium Sulfide [23].

$$
\mathrm{NaOH}(\mathrm{aq})+\mathrm{H}_{2} \mathrm{~S}(\mathrm{aq}) \leftrightarrow \mathrm{NaHS}(\mathrm{aq})+\mathrm{H}_{2} \mathrm{O}(\mathrm{l})
$$

The reaction mechanism proposed in a first stage explains the formation of sodium sulphide $\left(\mathrm{Na}_{2} \mathrm{~S}\right)$ given by (Eq. 7), and crystals of sodium sulfide with the (Eq.3) that is favored if the temperature is higher than $50^{\circ} \mathrm{C}$.

At temperatures below $50^{\circ} \mathrm{C}$, the formation of $\mathrm{Na}_{2} \mathrm{~S} .9 \mathrm{H}_{2} \mathrm{O}$ crystals (s) explained with (Eq. 10) is favored. Dehydration of this crystal can occur at temperatures above $50{ }^{\circ} \mathrm{C}$ [24], which can be explained by the inverse process of (Eq. 10), when the temperature is higher $\left(<83^{\circ} \mathrm{C}\right)$, the dehydration of the crystals of $\mathrm{Na}_{2} \mathrm{~S} .5 \mathrm{H}_{2} \mathrm{O}$ (s) can be given $[24,25,26]$, and can be explained with Eqs. (11 and 12) [27]. There are also other forms of dehydration of $\mathrm{Na}_{2} \mathrm{~S}_{5} \mathrm{H}_{2} \mathrm{O}$ crystals in species such as $\mathrm{Na}_{2} \mathrm{~S} .0 .5 \mathrm{H}_{2} \mathrm{O}$ [28].

$$
\begin{aligned}
& \mathrm{Na}_{2} \mathrm{~S} .5 \mathrm{H}_{2} \mathrm{O}(\mathrm{s})+4 \mathrm{H}_{2} \mathrm{O}(\mathrm{l}) \stackrel{T<50^{\circ} \mathrm{C}}{\longleftrightarrow} \mathrm{Na}_{2} \mathrm{~S} .9 \mathrm{H}_{2} \mathrm{O}(\mathrm{s}) \\
& \mathrm{Na}_{2} \mathrm{~S} .5 \mathrm{H}_{2} \mathrm{O}(\mathrm{s}) \stackrel{T<83^{\circ} \mathrm{C}}{\longrightarrow} \mathrm{Na}_{2} \mathrm{~S} .2 \mathrm{H}_{2} \mathrm{O}(\mathrm{s})+3 \mathrm{H}_{2} \mathrm{O}
\end{aligned}
$$

$$
\mathrm{Na}_{2} \mathrm{~S} .2 \mathrm{H}_{2} \mathrm{O}(\mathrm{s}) \leftrightarrow \mathrm{Na}_{2} \mathrm{~S}(\mathrm{aq})+2 \mathrm{H}_{2} \mathrm{O}
$$

Stage 2 of this mechanism explains the formation of sodium sulhydrate. Gaseous hydrogen sulfide is absorbed by 
the aqueous solution [29]. $\mathrm{H}_{2} \mathrm{~S}$ absorption in the aqueous solution of sodium sulphide is high even in sodium hydroxide solutions [30] where it will finally dissociate in sulfur ions depending on the $\mathrm{pH}$ of the medium [31]. Under unfavorable conditions, the desorption of hydrogen sulfide can occur, transferring the $\mathrm{H}_{2} \mathrm{~S}$ from the aqueous solution to the gas phase [32] explained with (Eq.13).

$$
\mathrm{H}_{2} \mathrm{~S}(\mathrm{~g}) \leftrightarrow \mathrm{H}_{2} \mathrm{~S}(\mathrm{aq})
$$

Hydrolysis of hydrogen sulphide generates disulphide ions (HS) $[2,3,33]$, which leads to a decrease in $\mathrm{pH}$ due to the presence of hydronium ions [34]. The balance between $\mathrm{H}_{2} \mathrm{~S}$, $\mathrm{HS}^{-}$, and $\mathrm{S}^{2-}$ is explained with Eqs. (13-15).

$$
\begin{aligned}
& \mathrm{H}_{2} \mathrm{~S}(\mathrm{aq})+\mathrm{H}_{2} \mathrm{O}(\mathrm{l}) \leftrightarrow \mathrm{HS}^{-}(\mathrm{aq})+\mathrm{H}_{3} \mathrm{O}^{+} \\
& \mathrm{HS}^{-}(\mathrm{aq})+\mathrm{H}_{2} \mathrm{O}(\mathrm{l}) \leftrightarrow \mathrm{S}^{2-}(\mathrm{aq})+\mathrm{H}_{3} \mathrm{O}^{+}
\end{aligned}
$$

Hydrogen sulfide, dissolved in water, is a very weak acid that undergoes ionizations with pK1 of 7 , at $25^{\circ} \mathrm{C}$ and pK2 of 12.92 at $25^{\circ} \mathrm{C}$ for Eqs. 15 and 16 respectively $[35,36]$. For an advanced study of $\mathrm{H}_{2} \mathrm{~S}, \mathrm{HS}^{-}$, and $\mathrm{S}^{-2}$ equilibria (in aqueous solutions), Petrucci and Moews propose several methods to calculate the concentrations of the species [37]. The formation of sodium sulfhydrate in an alkaline medium $\mathrm{pH}<10$ is explained by taking into account that in the equilibrium there is a higher proportion of $\mathrm{HS}^{-}$ions and the sulphurous ions are transformed into disulphide ions, explained with Eqs 16 and 17.

$$
\begin{aligned}
\mathrm{S}^{2-}(\mathrm{aq})+\mathrm{H}_{3} \mathrm{O}^{+}(\mathrm{aq}) & \leftrightarrow \mathrm{HS}^{-}(\mathrm{aq})+\mathrm{H}_{2} \mathrm{O}(\mathrm{l}) \\
2 \mathrm{Na}^{+}+2 \mathrm{HS}^{-}(\mathrm{aq}) & \leftrightarrow 2 \mathrm{NaHS}(\mathrm{aq})
\end{aligned}
$$

Due to the deficiency of sulfur ions in the reaction solution, the sodium sulfide crystals dissociate in sulfuric ions maintaining the concentration of $\mathrm{S}^{2-}$ and explained with Eqs (18 and 19).

$$
\begin{aligned}
\mathrm{Na}_{2} \mathrm{~S} .5 \mathrm{H}_{2} \mathrm{O}(\mathrm{s}) & \leftrightarrow \mathrm{Na}_{2} \mathrm{~S}(\mathrm{aq})+5 \mathrm{H}_{2} \mathrm{O}(\mathrm{l}) \\
\mathrm{Na}_{2} \mathrm{~S}(\mathrm{aq}) & \leftrightarrow \mathrm{S}^{2-}(\mathrm{aq})+2 \mathrm{Na}^{+}(\mathrm{aq})
\end{aligned}
$$

The presence of $\mathrm{CO}_{2}$ and $\mathrm{O}_{2}$ in the gas stream leaving the ADTF reactor generates unwanted reactions when the gases are brought into contact with the sodium hydroxide (Eq 20) in the absorbers $[20,21] . \mathrm{CO}_{2}$ absorption causes unnecessary caustic usage, contamination of the NaHS product solution with carbonate salts(Eq. 21), and potential plugging and fouling of process equipment with carbonate salt solids [20].

$$
\mathrm{CO}_{2}(\mathrm{aq})+\mathrm{NaOH}(\mathrm{aq}) \rightarrow \mathrm{NaHCO}_{3}(\mathrm{aq})
$$

On the other hand, the oxygen in the air reacts with $\mathrm{NaHS}$ and $\mathrm{Na}_{2} \mathrm{~S}$ to give undesired products such as $\mathrm{Na}_{2} \mathrm{CO}_{3}, \mathrm{Na}_{2} \mathrm{~S}_{2}$, $\mathrm{Na}_{2} \mathrm{~S}_{2} \mathrm{O}_{3}$, and $\mathrm{Na}_{2} \mathrm{SO}_{4}$, this is observed in the pulp and paper industry [38]. $\mathrm{CO}_{2}$ and $\mathrm{O}_{2}$ come from the air, these can enter the reactor through the phosphorus pentasulfide feed system or through the reactor seals. During the industrial process the control of these gases is achieved by making a vacuum in the ADTF reactor. Fig. (1) shows the proposed mechanism where the presence of the three phases is observed as well as the species involved in the formation of sodium sulfhydrate. It shows the summary of the chemical processes that during the absorption of $\mathrm{H}_{2} \mathrm{~S}$ in a solution of sodium sulfhydrate saturated with sodium sulfide, where the presence of the three phases is observed. The mechanism presented is an extension of the AlTarazi model [39] of a liquid gas contactor for formation of crystal and aggregates.

$$
\mathrm{NaHCO}_{3}(\mathrm{aq})+\mathrm{NaOH}(\mathrm{aq}) \rightarrow \mathrm{Na}_{2} \mathrm{CO}_{3}(\mathrm{aq})+\mathrm{H}_{2} \mathrm{O}
$$

The hydrolysis of NaHS can also occur to form $\mathrm{H}_{2} \mathrm{~S}$, and can be appreciable and sensitive to small variations of $\mathrm{pH}$ of neutral aqueous solutions [40]. Multiphase reactors are widely used in chemical industries because they offer high flexibility and allow appropriate conditions according to the requirements of the chemical reaction [41]. To maintain the phases in contact, an efficient system [42] of agitation is necessary, which allows keeping balanced the amounts of the different substances in each phase [43, 44]. The wide range of agitation devices (and the variety of impellers) and geometric parameters of the system allows to select a precise combination for the intended application [41]. In these types of reactors, under the action of the impeller or liquid agitation device, it allows the suspension of solids [42] and the dispersion of the gas phase (entering through the bottom of the container and close to the impeller), in such a way that the contact between the three phases is favored [45]. According to the phase diagram (see Fig. 2) of the $\mathrm{Na}_{2} \mathrm{~S}-\mathrm{H}_{2}$ system, if the reactor will be worked in a system formed only by sodium sulfide and water, it can be seen that we have two regions where two phases are present, such as $\mathrm{L}+\mathrm{C} 1$ and $\mathrm{L}+\mathrm{C} 2$.

The objective of this research was to study the manufacture of sulphides, specifically sodium sulphides, in an isothermal multiphase chemical reactor to produce concentrated aqueous solutions of sodium sulfhydrate greater than $40 \%$ (NAHS $42-45 \%$ ) from chemical reactions in a Ternary Gas-LiquidSolid system, recovering the hydrogen sulfide $\left(\mathrm{H}_{2} \mathrm{~S}\right)$ generated during the industrial production of dithiophosphoric acids.

For which we propose to develop a more attractive process by reducing the temperature of the process with respect to the technologies currently used in this area. 


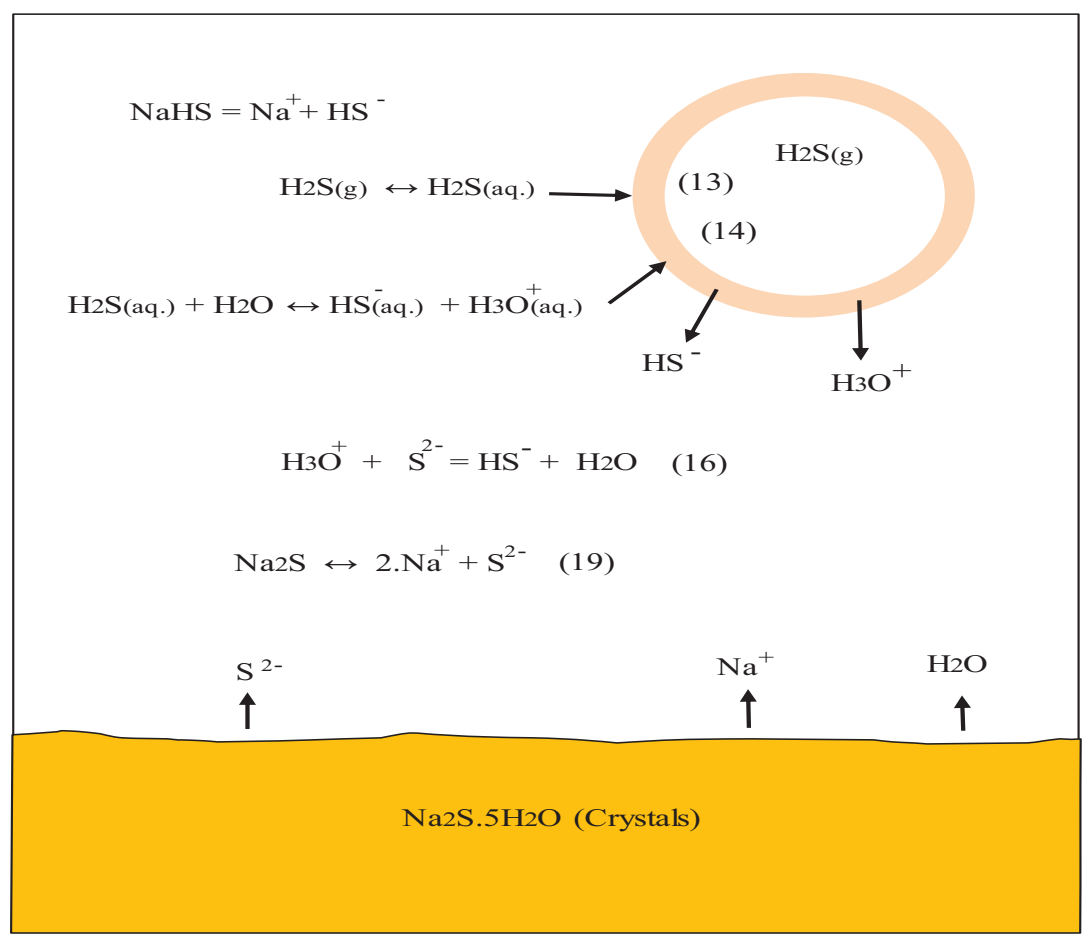

Fig. (1). Processes of absorption of $\mathrm{H}_{2} \mathrm{~S}$ in a solution of sodium sulfhydrate saturated with sodium sulphide.

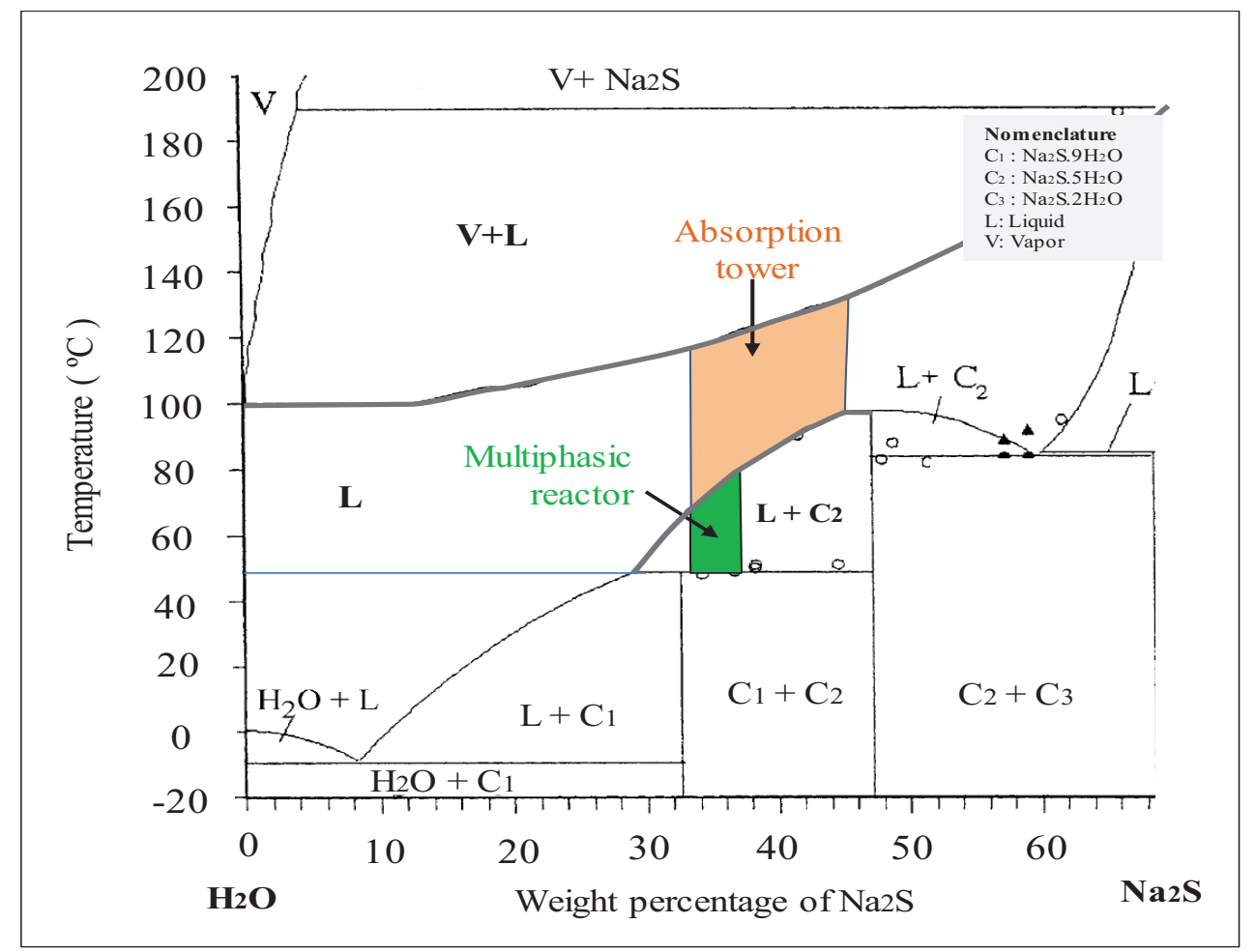

Fig. (2). Region of operation of a multiphase reactor starting only with aqueous solutions of $\mathrm{Na}_{2} \mathrm{~S}$ [25].

\section{MATERIALS AND METHODS}

\section{1. $\mathrm{H}_{2} \mathrm{~S}$ and ADTF Production}

Before indicating the characteristics of the reactor for this study, first we give the general guidelines of how hydrogen sulfide is generated in the Reactivos Nacionales S.A Company, which is the main problem we are trying to solve. The production of dithiophosphoric acids (ADTF) is carried out in a stirred tank-type semicontinuous reactor, where the phosphorus pentasulfide and a specific alcohol mentioned above are 
reacted. On alcohol at $90^{\circ} \mathrm{C}$, the phosphorus pentasulfide is added, the chemical reaction produces the ADTF and $\mathrm{H}_{2} \mathrm{~S}$. The reactor is maintained at a pressure of $-20 \mathrm{mmH}_{2} \mathrm{O}(-196.14 \mathrm{~Pa})$, and a production batch takes 6 hours. Table 1 shows the production of $\mathrm{H}_{2} \mathrm{~S}$ depending on the alcohol used. The raw materials are industrial grade at $99 \%$ and theoretically generate $92 \mathrm{~kg} \mathrm{H}_{2} \mathrm{~S}$ for each production batch, according to the production record of ADTF and the balance of material are recovered $90.4 \mathrm{~kg} \mathrm{H}_{2} \mathrm{~S}$, are recovered, which represents $98.3 \%$ recovery of the theoretic value. The $\mathrm{H}_{2} \mathrm{~S}(\mathrm{~g})$ for its treatment is bubbled in a stirred tank with a dilute solution of $\mathrm{Na}_{2} \mathrm{~S}-\mathrm{NaOH}$ or sent to the scrubber where diluted solutions of sodium sulphide are obtained with a concentration by 20 to $25 \%$ weight. Faced with this problem, a technological alternative is sought that allows to dispose the residual $\mathrm{H}_{2} \mathrm{~S}$ in such a way that it improves the economy of the main process.

When monitoring the values recorded by the pressure transmitter it is common to find the following pressure patterns (see Fig. 3), $\mathrm{H}_{2} \mathrm{~S}$ flow (see Fig. 4) and the temperature and $\mathrm{pH}$ profiles (see Fig. 5) during the ADTF production process.

Table 1. Stoichiometric formulation for the production of ADTF.

\begin{tabular}{|c|c|c|c|c|}
\hline Products & Alcohol (kg) & $P_{4} S_{10}(\mathrm{~s})(\mathrm{kg})$ & ADFT (kg) & $\mathrm{H}_{2} \mathrm{~S}$ (kg) \\
\hline ADTF from isopropanol alcohol & 648.8 & 600 & 1156.8 & 92 \\
\hline ADTF from isobutanol alcohol & 800.3 & 600 & 1308.3 & 92 \\
\hline ADTF from isopentanol alcohol & 951.8 & 600 & 1459.8 & 92 \\
\hline
\end{tabular}

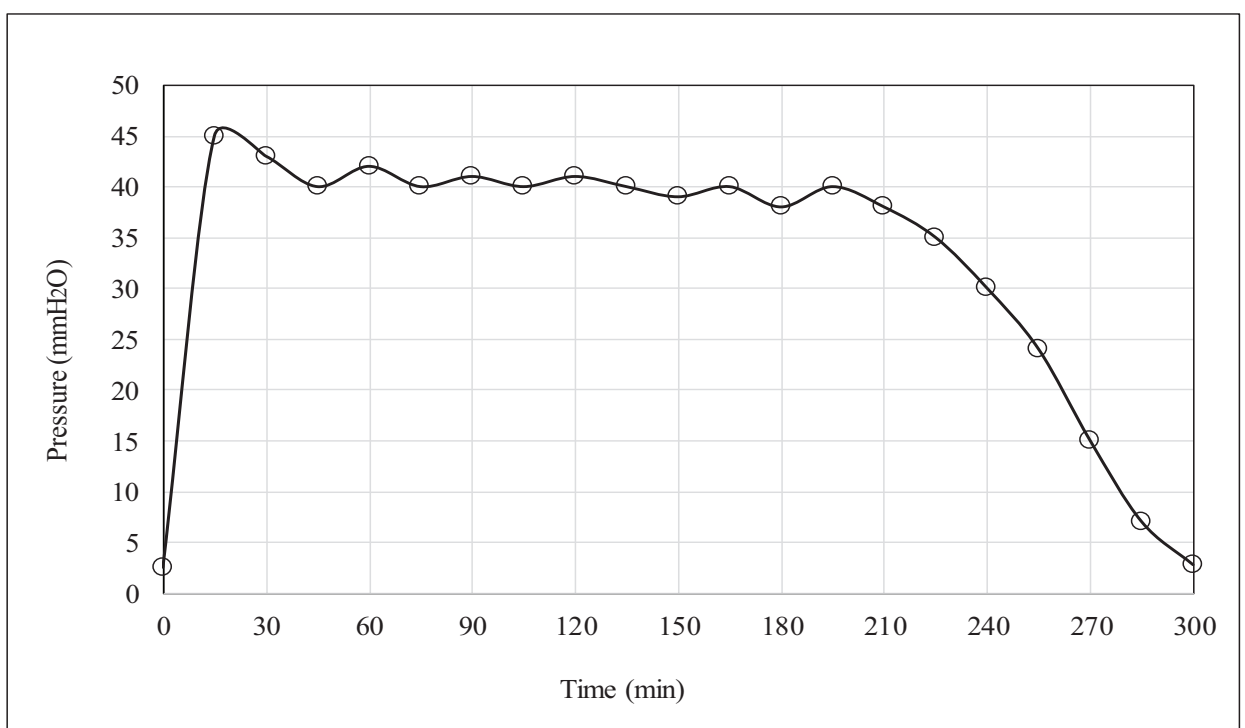

Fig. (3). Pressure pattern in the semicontinuous stirred tank industrial reactor during the production of ADTF (Reactivos Nacionales S.A., Lima Peru).

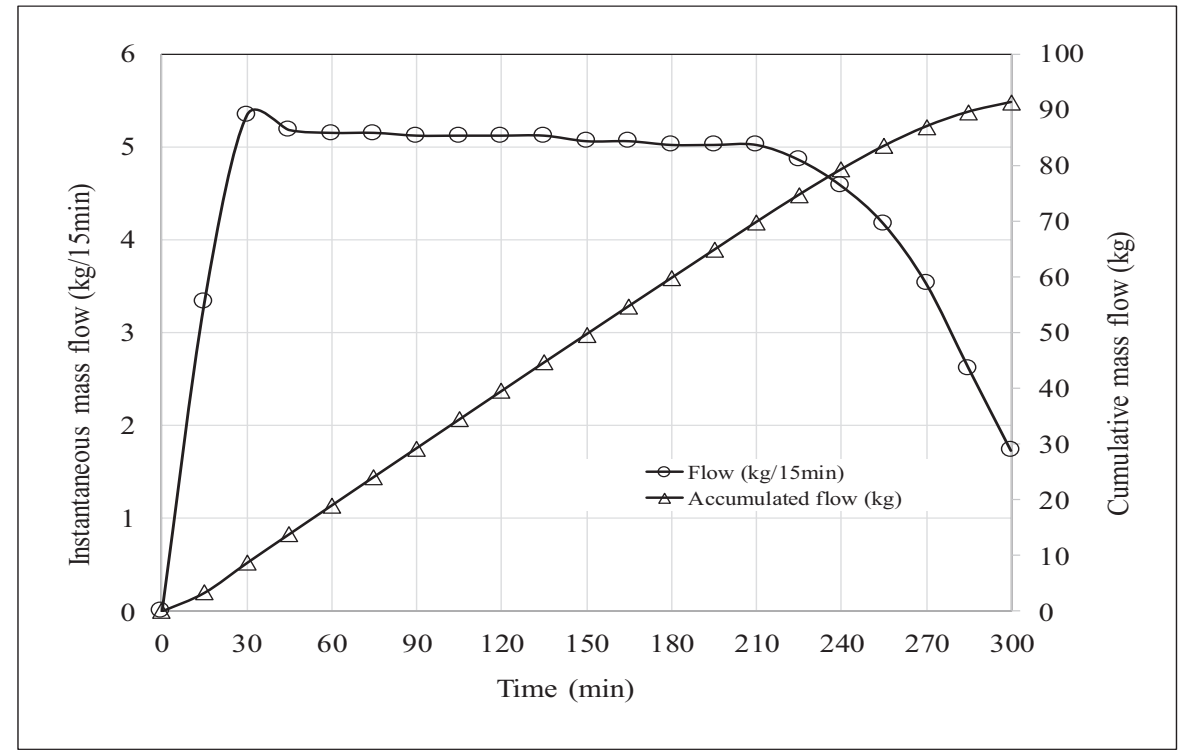

Fig. (4). $\mathrm{H}_{2} \mathrm{~S}$ flow pattern during a typical ADTF production operation. 


\subsection{Specification of $\mathrm{H}_{2} \mathrm{~S}$ Flow}

The ADTF production plant has a flowmeter at the outlet of the condensers where the gas output is monitored at room temperature $\left(22^{\circ} \mathrm{C}\right)$ throughout the reaction process. Figs. $(4$ and 5) show, the $\mathrm{H}_{2} \mathrm{~S}$ flow pattern and temperature profile in the industrial reactor during ADTF production. The mass flow is calculated with the following equation:

$$
F\left(\mathrm{kgH}_{2} \mathrm{~S} / \mathrm{min}\right)=K f * \sqrt{\Delta P * \rho \mathrm{H} 2 \mathrm{~S}}
$$

The operating parameters of the flowmeter are specified taking into account the following: Kf: flowmeter constant $0.045 \mathrm{~m}^{2}\left(22^{\circ} \mathrm{C}, 101.325 \mathrm{kPa}\right) . \Delta \mathrm{P}: \mathrm{mmH} 2 \mathrm{O} \rho\left(\mathrm{H}_{2} \mathrm{~S}\right):(1.42$ $\mathrm{kg} \cdot \mathrm{m}^{-3}, 21.1^{\circ} \mathrm{C}$ and $\left.101.325 \mathrm{kPa}\right)$ or $\left(1.220 \mathrm{~kg} \cdot \mathrm{m}^{-3}, 21.1^{\circ} \mathrm{C}\right.$ and $101.325 \mathrm{kPa})$.

\subsection{Characteristics of the Stirred Tank Reactor: Batch Mode Experimental}

The configuration of the stirred tank pilot reactor used for this study is shown in Fig. (6). The main parts that make up the pilot reactor are: (1) a reactor with variable agitation; (2) a pH meter; (3) A temperature meter; (4) an $\mathrm{H}_{2} \mathrm{~S}$ analyzer; (5) heating and cooling medium. Very close to our system is the industrial semicontinuous reactor for the production of ADTF, where $\mathrm{H}_{2} \mathrm{~S}$ is produced, which was conveniently used for experimental development. The reactor planned for this study operates at temperatures lower than the temperatures of recovery technologies by absorption towers (less than $70^{\circ} \mathrm{C}$ ) in order to facilitate the $\mathrm{H}_{2} \mathrm{~S}$ absorption in the reaction medium.

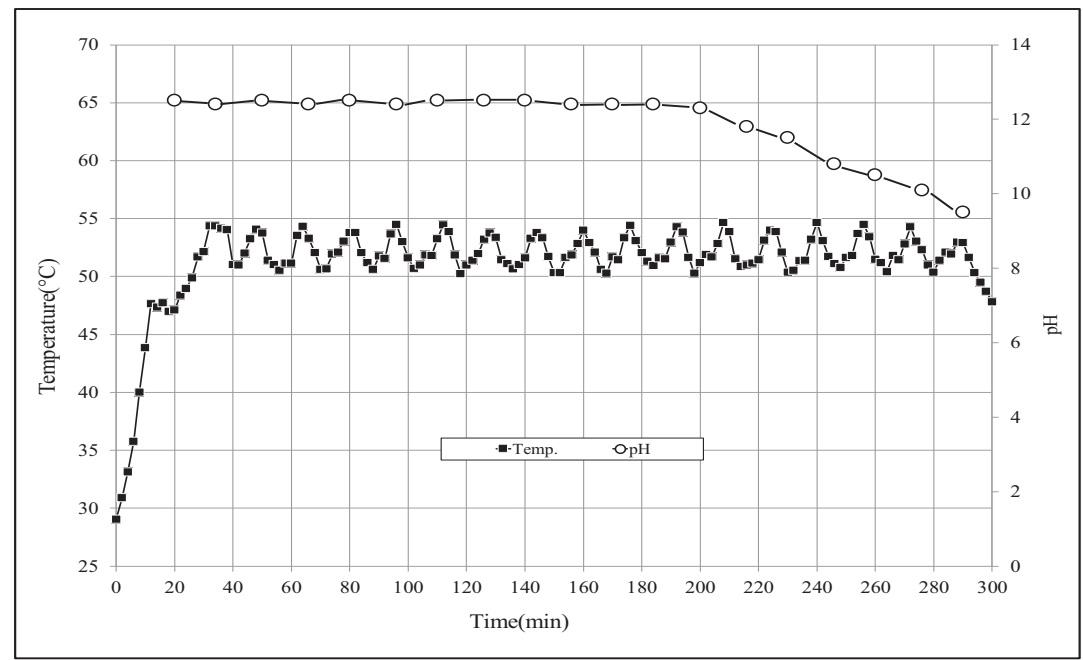

Fig. (5). Temperature profile in the industrial reactor during ADTF production.

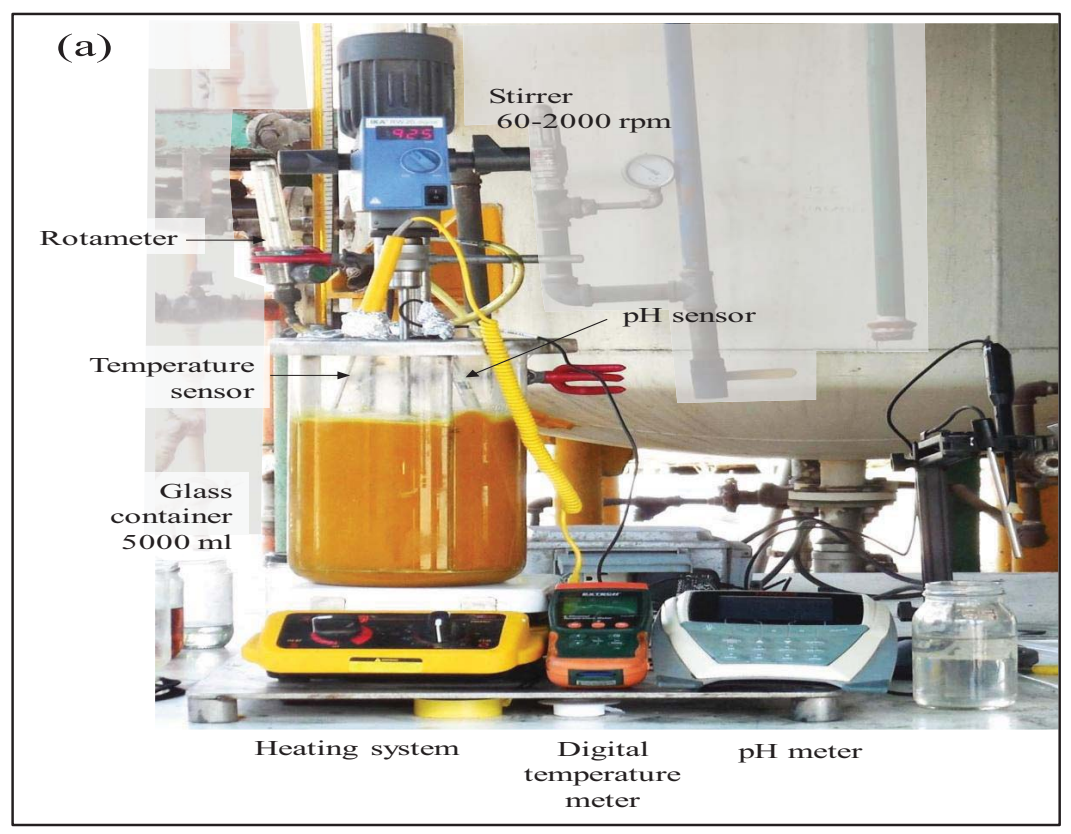



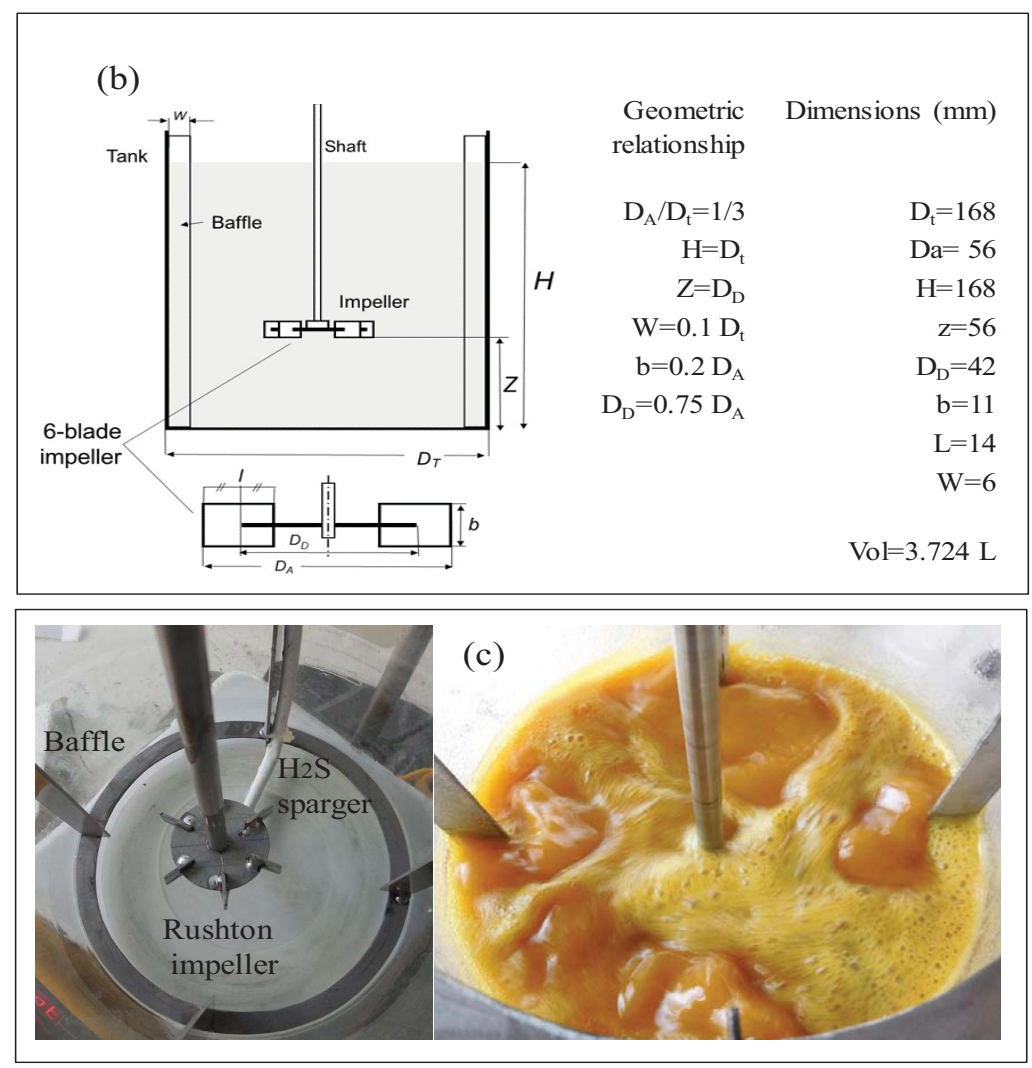

Fig. (6). (a) Configuration of the stirred tank pilot reactor (b) Geometric configuration of the pilot reactor [42, 46], (c) Impeller installed in the pilot reactor, the deflectors and the $\mathrm{H}_{2} \mathrm{~S}$ bubbler are observed. Where: $\mathrm{D}_{\mathrm{T}}$ is tank diameter, $\mathrm{D}_{\mathrm{D}}$ is impeller diameter, $\mathrm{W}$ is baffle width, I is impeller blade length.

For the experimental development, a cylindrical glass vessel of $168 \mathrm{~mm}$ internal diameter and $210 \mathrm{~mm}$ in height was used, with a liquid level equal to the tank diameter, with a total volume of $5 \mathrm{~L}$. The agitation system described by [46], was applied to design the components of the stirred tank, such as the impeller and deflectors (Fig. 6). Similar geometric relationships (Fig. 6b) are also shown in [47, 48]; [49, 50, 51]. With this configuration there is available a reaction volume of 3.72 liters sufficient for the end pursued. The composition of the reaction mixture is $\mathrm{Na}_{2} \mathrm{~S}(13 \%)$, NaHS $(27 \%)$ and $\mathrm{H}_{2} \mathrm{O}$ $(60 \%)$ with an average density of $1.26 \mathrm{~g} / 1$ at $50{ }^{\circ} \mathrm{C}$. The reactor can treat $4650 \mathrm{~g}$ of reaction mixture with a final volume of 3.910 liters, which is equivalent to approximately $5000 \mathrm{~g}$ of NaHS when the final product is formed. Fig. (6) shows the detailed dimensions of the reactor used for the experiments. The rotameter was calibrated for a water column of $218 \mathrm{~mm}$ $\mathrm{H}_{2} \mathrm{O}$ with flow rates ranging from 0.1 vvmin (at $25^{\circ} \mathrm{C}$ ) to 0.8 vvm (at $25^{\circ} \mathrm{C}$ ). Take into account that vvmin represents the volume of gas per volume of the reaction medium per minute. Taking into account that the volume of the medium is 3.8 liters of biphasic mixture (composed of crystals of sodium sulfide and aqueous solution of $\mathrm{NaHS}$ ) we have: $\left(0.8\right.$ liters $\mathrm{H}_{2} \mathrm{~S} / \mathrm{min}=$ 0.21 vvmin, 1.6 liters $\mathrm{H}_{2} \mathrm{~S} / \mathrm{min}=0.42$ vvmin, liters $\mathrm{H}_{2} \mathrm{~S} / \mathrm{min}=$ 0,85 vvmin). To measure the presence of $\mathrm{H}_{2} \mathrm{~S}$ that could escape from the reactor, a gas detector has been used (Brand: Aeroqual, Model: Series - 200, Sensor: EHT / EHT2 range: 0 $100 \mathrm{ppm}$, peaks up to $300 \mathrm{ppm})$. The device is a precise meter for the measurement of $\mathrm{H}_{2} \mathrm{~S}$ concentrations in the air or in gas streams. The gas detector has a built-in pump in the head that sucks gases from the reactor to be analyzed. When there is a high presence of $\mathrm{H}_{2} \mathrm{~S}$ in the pilot reactor, a large amount of foams will be observed on the reaction medium. So in these circumstances the gas sensor should be disconnected to avoid saturation of the catalytic sensor.

\section{RESULTS AND DISCUSSION}

\subsection{Determination of the Bubble Diameter of $\mathrm{H}_{2} \mathrm{~S}$}

The bubble size cannot be determined by mathematical models for this type of reactors, because the system is a complex mixture, that is why we have proceeded to measure directly by photographic captures using the microscope (UNIMAKE, USB Digital Microscope 1000X) to determine the size of the bubbles closest to the surface of the reactor.

The photographic capture (Digital Camera, Nikon Coolpix S6500) was made stopping untimely agitation and gas entering the reactor. The measurement must be fast because the bubbles reduce their size since they are absorbed in the aqueous solution or they abandon the reaction medium. A uniform distribution of the bubbles in the liquid is observed and it can be inferred that the bubbles have diameters of less than $300 \mu \mathrm{m}$ measured at a reaction temperature of $53^{\circ} \mathrm{C}$, stirring speed of $700 \mathrm{rpm}$ and a flow of $\mathrm{H}_{2} \mathrm{~S} 0.4$ vvmin. The bubbles were (Fig. 7a) $(\mathrm{A}=300 \mu \mathrm{m}, \mathrm{B}=80 \mu \mathrm{m}, \mathrm{C}=60 \mu \mathrm{m})$. The bubbles are of $\mathrm{H}_{2} \mathrm{~S}$ and it occurs quite frequently when the reaction solution is almost saturated with $\mathrm{H}_{2} \mathrm{~S}$ and when NaHS is already formed in its entirety (the $\mathrm{pH}$ of the reaction mixture is around 8 ). On the 
other hand, when air enters the system, $\mathrm{O}_{2}$ becomes thiosulphate and collapses, and if there are bubbles, it is due to Nitrogen $\left(\mathrm{N}_{2}\right)$. The vacuum pressure prevents the entry of air, the gas flow meter does not show the passage of any gas, and if $\mathrm{CO}_{2}$ has passed must be negligible because the content of thiosulphate is minimal and almost always maintained at values of $100 \mathrm{mg} / \mathrm{L}$, and has no impact on the specification of the final product. Fig. (7b) shows the multiphase reactor in operation, the foam that is formed when the flow rate of $\mathrm{H}_{2} \mathrm{~S}$ $(\mathrm{g})$ is much greater than 0.8 vvmin is observed. This foam mattress arrives until the empty space of the reactor is reached. In other research work [52], the photographic method was used for this purpose, where the bubble diameters were evaluated for selected bubbles in different locations at different times. The foam formed from sodium sulfide crystals $\mathrm{Na}_{2} \mathrm{~S}_{5} \mathrm{H}_{2} \mathrm{O}$, when cooled, crystallizes and adheres to the walls of the reactor generating various problems such as the impediment of the flow of $\mathrm{H}_{2} \mathrm{~S}$. The hydration temperature of $\mathrm{Na}_{2} \mathrm{~S}$ is $73^{\circ} \mathrm{C}$ [28], and the dehydration temperature is $80{ }^{\circ} \mathrm{C}$ (Eq. 11) [24, 53], which represents a process of hysterisis. Mechanically, stirred tank reactors in which the gas phase is dispersed by means of a dispenser and/or a stirrer are used in many chemical processes (gas absorption etc) [54]. Stirred vessels are very commonly used for gas-liquid reactions on account of their flexibility and good performance for mass and heat transfer [55]. When a single phase is present, the fluid flow induced by the impellers is relatively easy to predict. The addition of a second phase to the reactor increases the hydrodynamic system complexity [ 54 , 56]. Gas flow pattern is important. It controls the degree of recirculation and backmixing of the gas phase, which in turn determines the mean concentration driving force for mass transfer. In the homogeneous regime in an agitated vessel, the superficial gas velocity, $\mathrm{vS}<0.02$ to $0.03 \mathrm{~m} / \mathrm{s}$, and the bubbles have a monomodal size distribution with a small mean size, generally between 0.5 and $4 \mathrm{~mm}$. Here, the impeller controls the flow pattern and bubble size [55]. Good mass transfer performance requires large interface area between gas and liquid (resulting directly from small bubble size and high gas fraction, given the fixed gas rate), and a high mass transfer coefficient (associated with local levels of turbulence) [55].

\subsection{Formation of $\mathrm{Na}_{2} \mathrm{~S} .5 \mathrm{H}_{2} \mathrm{O}$ Crystals at $50-55{ }^{\circ} \mathrm{C}$}

It is important to bear in mind that the formation of $\mathrm{Na}_{2} \mathrm{~S} .9 \mathrm{H}_{2} \mathrm{O}$ crystals occurs in a temperature range of 30 to $35^{\circ}$ $\mathrm{C}$, with a low content of $\mathrm{Na}_{2} \mathrm{~S} .5 \mathrm{H}_{2} \mathrm{O}$. The reaction parameters for the transformation of sodium sulfide crystals in the pilot reactor were the following: Stirring speed: $700 \mathrm{rpm}$; initial temperature: $26^{\circ} \mathrm{C}$, maximum reaction temperature: $30^{\circ} \mathrm{C}$, stirring time 30 minutes. The can be explained taking into account (Eq. 2), in addition to:

$$
\begin{aligned}
& \mathrm{Na}_{2} \mathrm{~S}+9 \mathrm{H}_{2} \mathrm{O} \leftrightarrow \mathrm{Na}_{2} \mathrm{~S} .9 \mathrm{H}_{2} \mathrm{O}(\mathrm{s}) \\
& \mathrm{Na}_{2} \mathrm{~S}+5 \mathrm{H}_{2} \mathrm{O} \leftrightarrow \mathrm{Na}_{2} \mathrm{~S} .5 \mathrm{H}_{2} \mathrm{O}(\mathrm{s})
\end{aligned}
$$

When the temperature of material is lower than its melting point, crystalline hydrate will wholly or partially strip its water of crystallization. When the temperature decreases, $\mathrm{Na}_{2} \mathrm{~S}(\mathrm{~s})$ adsorbs water and transforms into $\mathrm{Na}_{2} \mathrm{~S} \cdot \mathrm{nH}_{2} \mathrm{O}(\mathrm{s})$. Under many circumstances, such hydration heat could be much higher than dissolution heat [57]. A curve showing the solubility of hydrates of $\mathrm{Na}_{2} \mathrm{~S}$ can be consulted in [58]. If crystallization with agitation takes place much longer (48 hours) and with temperatures of $25^{\circ} \mathrm{C}$, most of the $\mathrm{Na}_{2} \mathrm{~S} .5 \mathrm{H}_{2} \mathrm{O}$ will have been transformed into $\mathrm{Na}_{2} \mathrm{~S} .9 \mathrm{H}_{2} \mathrm{O}$ crystals with particle size that will be around $4 \mathrm{~mm}$. Working at low temperatures with a high concentration of crystals (Fig. 8) causes suspension problems in the reaction mixture, blockage of the bubbler holes and makes it difficult to react the reaction mixture with $\mathrm{H}_{2} \mathrm{~S}$ for the conversion of $\mathrm{Na}_{2} \mathrm{~S}$ to NaHS. With formulation of Table 2 and reaction conditions (stirring speed: $700 \mathrm{rpm}$; initial temperature: $26{ }^{\circ} \mathrm{C}$; maximum reaction temperature: $50{ }^{\circ} \mathrm{C}$; and stirring time: 30 minutes), mainly $\mathrm{Na}_{2} \mathrm{~S} .5 \mathrm{H}_{2} \mathrm{O}$ crystals are formed according to Eqs 2 and 3.

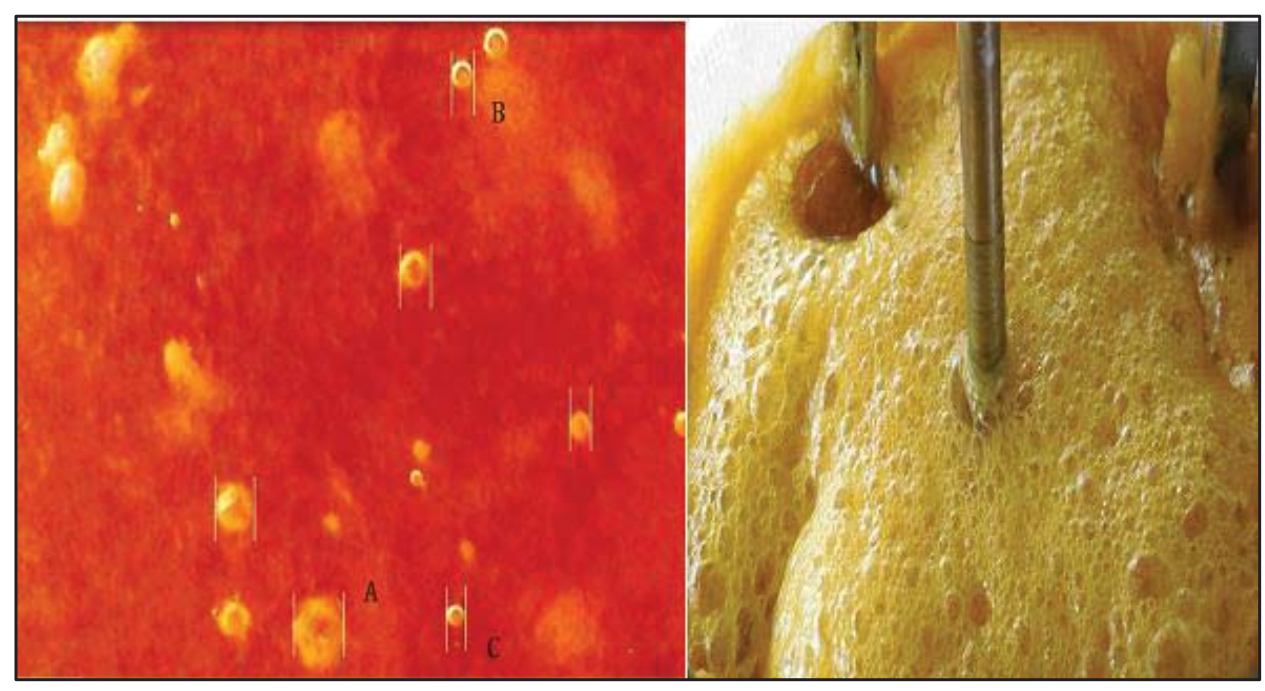

Fig. (7). (a) Distribution of $\mathrm{H}_{2} \mathrm{~S}$ bubbles in the multiphase reactor, (b) Foam crystals of $\mathrm{Na}_{2} \mathrm{~S}$ and water with $\mathrm{H}_{2} \mathrm{~S}$ bubbles. 
Table 2. The formulation for the crystallization test.

\begin{tabular}{|c|c|}
\hline Components & Quantify \\
\hline NaHS (43\%) & $3964 \mathrm{~g}$ \\
\hline$[\mathbf{N a H S}]$ & $43.20 \%$ \\
\hline$\left[\mathbf{N a}_{2} \mathbf{S}\right]$ & $0.20 \%$ \\
\hline $\mathbf{H}_{2} \mathbf{O}$ & $110 \mathrm{~g}$ \\
\hline $\mathbf{N a O H}(\mathbf{5 0} \%)$ & $638 \mathrm{~g}$ \\
\hline
\end{tabular}

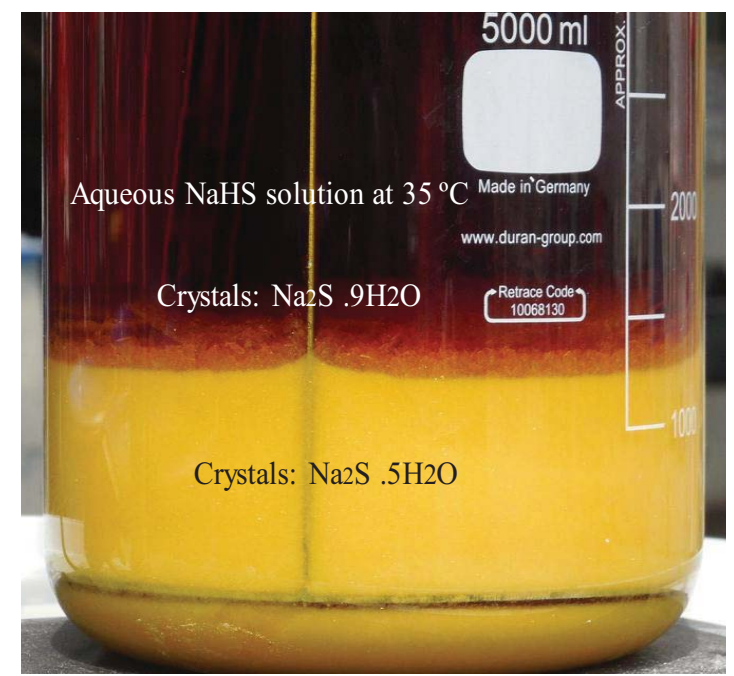

Fig. (8). Sodium sulfide crystals formed at $35^{\circ} \mathrm{C}$.

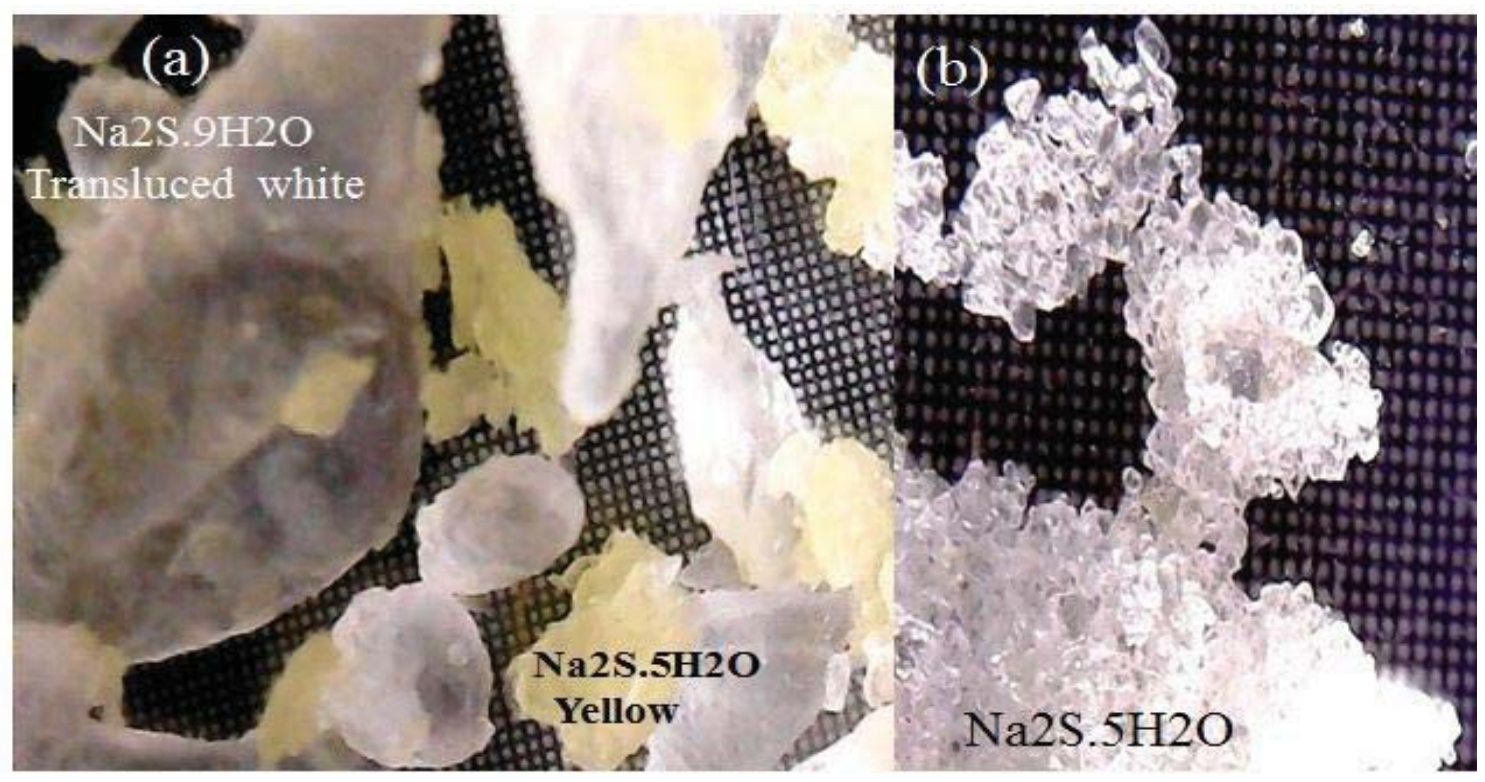

Fig. (9). Effect of temperature on the formation of $\mathrm{Na}_{2} \mathrm{~S}_{5} \mathrm{H}_{2} \mathrm{O}$ crystals: (a): $30-35^{\circ} \mathrm{C}$, (b) $50-55^{\circ} \mathrm{C}$.

With formulation of Table 2 and reaction conditions (stirring speed: $700 \mathrm{rpm}$; initial temperature: $26^{\circ} \mathrm{C}$; maximum reaction temperature: $50^{\circ} \mathrm{C}$; and stirring time: 30 minutes), mainly crystals of $\mathrm{Na}_{2} \mathrm{~S} .5 \mathrm{H}_{2} \mathrm{O}$ are formed which explains by Eqs 2 and 3. When the aqueous sodium hydroxide is contacted with the sodium sulfhydrate solution, the conversion to sodium sulfide crystals immediately occurs. The reaction is exothermic and instantaneous, and in less than 1 minute the NaHS is transformed into $\mathrm{Na}_{2} \mathrm{~S}$, the reaction mixture raises its temperature to $48{ }^{\circ} \mathrm{C}$. The amount of crystals obtained is $1047 \mathrm{~g}$, 
which represents $22 \%$ according to the weight of the mixture. The crystals show particle diameters less than $1500 \mathrm{~mm}$. The shape and distribution of the crystals is more homogeneous when the temperature is maintained in a range of $50{ }^{\circ} \mathrm{C}$ to 55 ${ }^{\circ} \mathrm{C}$. Dehydration of $\mathrm{Na}_{2} \mathrm{~S} .9 \mathrm{H}_{2} \mathrm{O}$ changes to a yellow color [25], indicating the presence of $\mathrm{Na}_{2} \mathrm{~S} 5 \mathrm{H}_{2} \mathrm{O}$, this effect is shown in Fig. (9).

\subsection{Influence of the Solid Content of the Reactioning Mixture in the Progression of the Reaction}

To confirm that the reaction mixture with a solids concentration of $22 \%\left(\mathrm{Na}_{2} \mathrm{~S}_{5} \mathrm{H}_{2} \mathrm{O}\right)$ has good reaction properties as opposed to solids concentrations of less than or greater than $22 \%$, three tests were organized where each reaction mixture ( $\mathrm{NaOH}$ and NaHS) form crystals of sodium sulphide $\left(\mathrm{Na}_{2} \mathrm{~S} .5 \mathrm{H}_{2} \mathrm{O}\right)$ (see Table 3) and finally react with hydrogen sulphide to give $43 \%$ NaHS. The amounts of NaHS used include stoichiometric amounts which will react with the sodium hydroxide and those which keep the crystals formed in suspension. The amounts of water used in the formulations allow to correct the final concentration of the product. The formulations used make it possible to initiate the reaction with the $\mathrm{H}_{2} \mathrm{~S}$ with a volume of reaction mixture of $3578 \mathrm{~mL}$ corresponding to the volume of reactor established to maintain the configuration of the reactor which is also object of analysis. The conditions of these tests were: reaction temperature $\left(50-55^{\circ} \mathrm{C}\right)$; agitation (impeller: $\left.700 \mathrm{rpm}\right)$; reaction time ( $2.25 \mathrm{hrs})$; and $\mathrm{H}_{2} \mathrm{~S}$ flow (0.41 vvmin). When the reaction mixtures were prepared with $\mathrm{NaOH}$ and $\mathrm{NaHS}$, the stirring was stopped for 30 minutes so that the $\mathrm{Na}_{2} \mathrm{~S}_{5} \mathrm{H}_{2} \mathrm{O}$ crystals formed sedimented while maintaining the reaction temperature at $50^{\circ} \mathrm{C}$. Fig. (10) shows the presence of solids $\left(\mathrm{Na}_{2} \mathrm{~S} 5 \mathrm{H}_{2} \mathrm{O}\right)$ in each case.

The presence of solid particles causes different results in gas-liquid and gas-liquid-solid systems. In gas-liquid systems, a higher agitation speed can effectively break bubbles into smaller ones and hinder the bubble coalescence. But this capacity is weakened when solid particles are introduced into the system because the particles reduce the velocity of fluid flow and may collide with bubbles [59]. For very fine particles $(<10 \mu \mathrm{m})$ at low solids concentration $(<0.6 \% \mathrm{v} / \mathrm{v})$ and very large particles $(>2000 \mu \mathrm{m})$ at high solids concentration $(>10 \%$ $\mathrm{v} / \mathrm{v})$, the trend is an increase in the gas holdup [60, 61]. Gasliquid-solid three-phase mechanically stirred tank reactors are widely applied in many industrial processes [59], where particles suspension are influenced in a complex manner by gassing [55]. When solid particles are added in gas-liquid systems, the better understanding of solid suspension and mass transfer is important to the design and scale-up of gas-liquidsolid stirred tank reactors $[59,62,63]$.

Reaction mixtures Test 1,2 and 3 are located within the biphasic region and the concentrations of the species will be displaced until $43 \%$ sodium sulfhydrate solutions are obtained. Fig. (11) shows the location of these points $\left(\mathrm{N}^{0} 1,2\right.$, and 3$)$. The shaded region shows the different ternary mixtures with good agitation properties. The reaction mixtures are reacted with the hydrogen sulfide with a gas flow rate of $0.41 \mathrm{vvmin}$ and the progress profile of the reaction is shown in Fig. (11). The reaction mixtures with 11,22 and $33 \%$ solids are reacted with the hydrogen sulfide with a gas flow rate of 0.41 vvmin and the progress profile of the reaction is shown in Fig. (12).

Table 3. Formulation to determine the ratio NaHS $43 \%$ / NaOH $50 \%$.

\begin{tabular}{|c|c|c|c|}
\hline Reagents & Test 1 & Test 2 & Test 3 \\
\hline $\mathrm{NaHS}, 43 \%$ & $4341 \mathrm{~g}$ & $3964 \mathrm{~g}$ & $3585 \mathrm{~g}$ \\
\hline [NaHS] & $43.40 \%$ & $43.40 \%$ & $43.40 \%$ \\
\hline$\left[\mathrm{Na}_{2} \mathrm{~S}\right]$ & $0.33 \%$ & $0.33 \%$ & $0.33 \%$ \\
\hline$\left[\mathrm{Na}_{2} \mathrm{CO}_{3}\right]$ & $<0.1 \%$ & $<0.1 \%$ & $<0.1 \%$ \\
\hline $\mathrm{H}_{2} \mathrm{O}$ & $60 \mathrm{~g}$ & $121 \mathrm{~g}$ & $181 \mathrm{~g}$ \\
\hline \multicolumn{4}{|l|}{ Reagents } \\
\hline $\mathrm{NaOH} \mathrm{50 \%}$ & $319 \mathrm{~g}$ & $538 \mathrm{~g}$ & $957 \mathrm{~g}$ \\
\hline $\mathrm{H}_{2} \mathrm{~S}(0.4$ vvmin $)$ & $137 \mathrm{~g}$ & $275 \mathrm{~g}$ & $412 \mathrm{~g}$ \\
\hline $\mathrm{NaHS}, 43 \% / \mathrm{NaOH}, 50 \%$ & 13.6 & 6.21 & 3.74 \\
\hline \multicolumn{4}{|l|}{ Mass balance } \\
\hline$\left[\mathrm{Na}_{2} \mathrm{~S}\right], \%$ & 6.89 & 13.46 & 20.02 \\
\hline$[\mathrm{NaHS}], \%$ & 35.14 & 26.95 & 18.74 \\
\hline$\left[\mathrm{H}_{2} \mathrm{O}\right], \%$ & 57.9 & 59.59 & 53.84 \\
\hline Crystals weight & $512 \mathrm{~g}(10.8 \%)$ & $1047 \mathrm{~g}(22.16 \%)$ & $1586 \mathrm{~g}(33.5 \%)$ \\
\hline Liquid weight & $4208 \mathrm{~g}$ & $3676 \mathrm{~g}$ & $3137 \mathrm{~g}$ \\
\hline Total weight & $4720 \mathrm{~g}$ & $4723 \mathrm{~g}$ & $4723 \mathrm{~g}$ \\
\hline Solid phase volume & $1052 \mathrm{~mL}(29 \%)$ & $1473 \mathrm{~mL}(41 \%)$ & $2526 \mathrm{~mL}(70 \%)$ \\
\hline Liquid phase volume & $2525 \mathrm{~mL}$ & $2105 \mathrm{~mL}$ & $1053 \mathrm{~mL}$ \\
\hline Total volume & $3577 \mathrm{~mL}$ & $3578 \mathrm{~mL}$ & $3579 \mathrm{~mL}$ \\
\hline
\end{tabular}




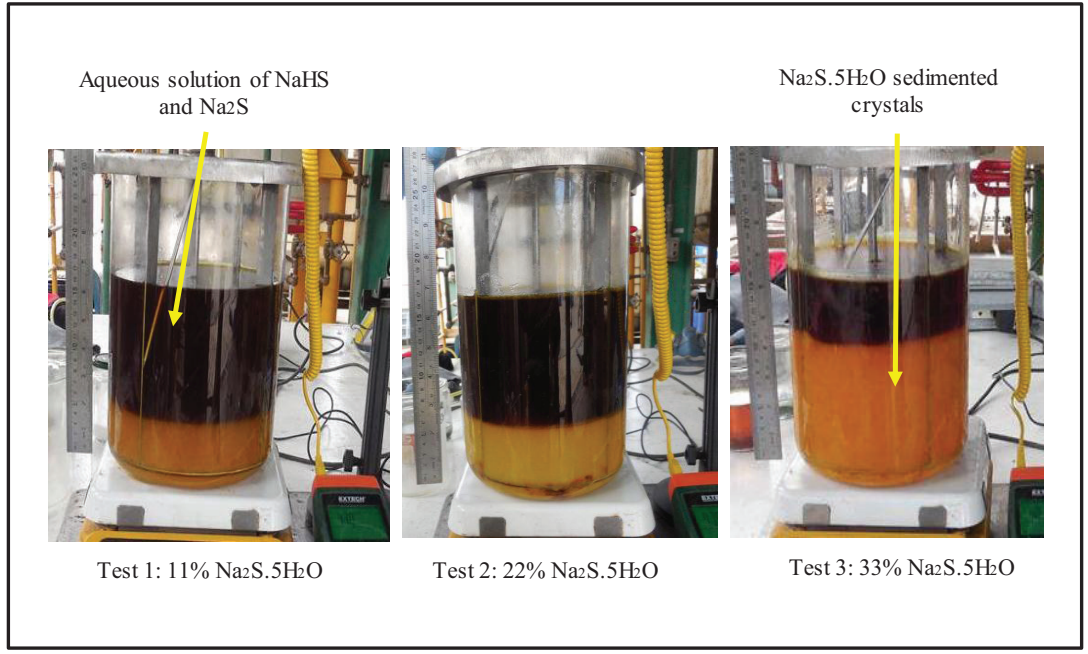

Fig. (10). Presence of solids $\left(\mathrm{Na}_{2} \mathrm{~S}_{5} \mathrm{H}_{2} \mathrm{O}\right)$ in the reaction mixture.

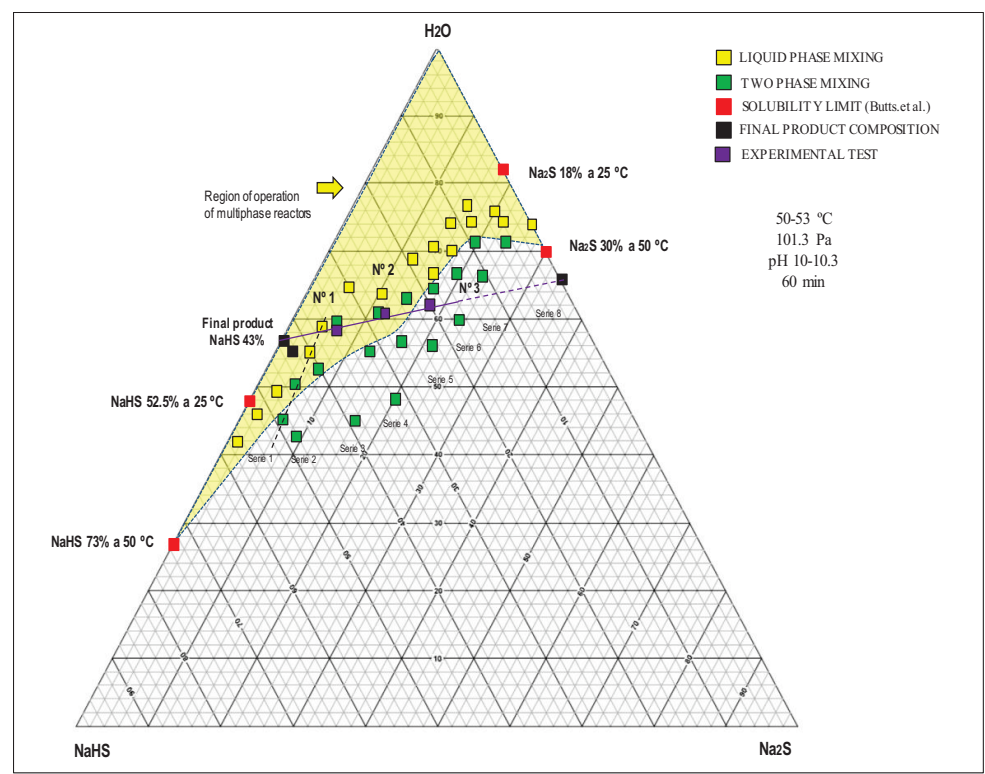

Fig. (11). Locating the test points in a ternary diagram $\mathrm{NaHS}-\mathrm{Na}_{2} \mathrm{~S}-\mathrm{H}_{2} \mathrm{O}$.

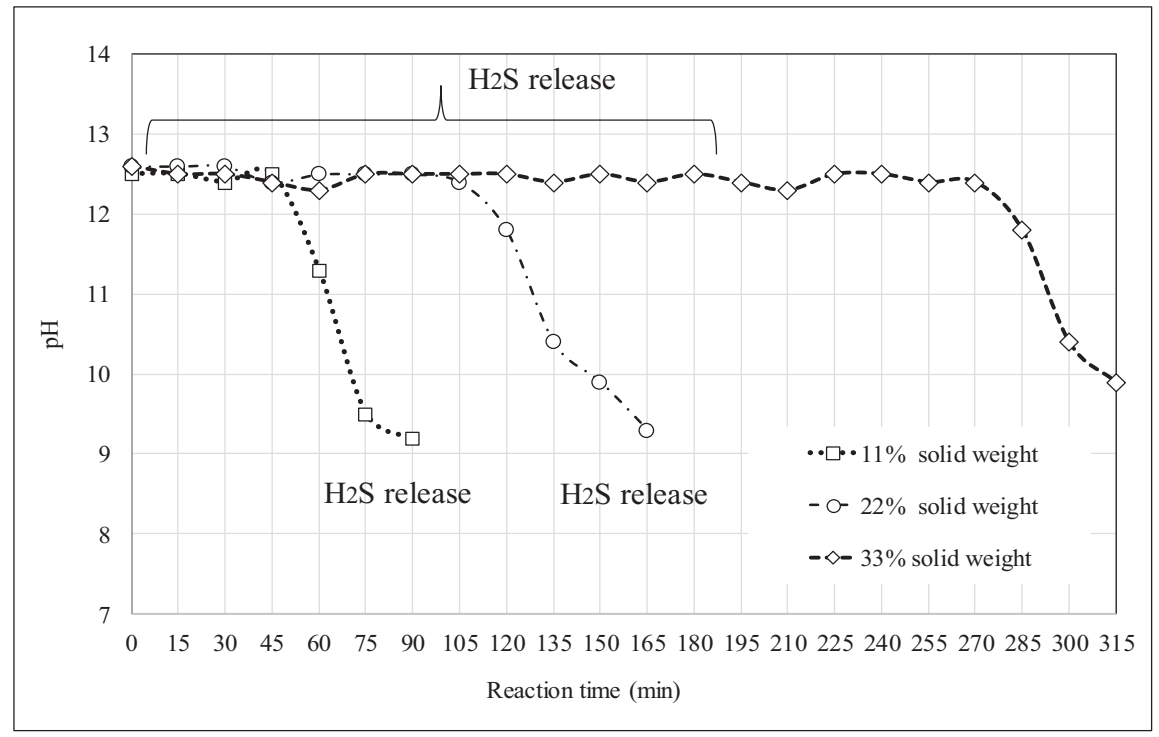

Fig. (12). Advance reaction with different solids contents in the reaction mixture: Effect on the $\mathrm{pH}$. 


\subsection{Influence of Temperature on the Absorption of $\mathrm{H}_{2} \mathrm{~S}$}

One of the most discussed topics in the treatment of $\mathrm{H}_{2} \mathrm{~S}$ is the low solubility of it in concentrated solutions of sodium sulfhydrate and sodium sulfide. To this end, four tests were organized at $50,60,70$, and $80^{\circ} \mathrm{C}$ in reaction solutions with an approximate of $40.5 \% \mathrm{NaHS}$ and $2.8 \% \mathrm{Na}_{2} \mathrm{~S}$. The volume of the solution was $3725 \mathrm{ml}$; the flow of $\mathrm{H}_{2} \mathrm{~S}$ was 0.12 vvmin $\left(\left(0.44 \mathrm{~L} \cdot \mathrm{min}^{-1}\right)\right.$ at $\left.25^{\circ} \mathrm{C}\right)$; and the impeller speed $700 \mathrm{rpm}$. The reaction solution under study at $50{ }^{\circ} \mathrm{C}$ does not have sodium crystals that disturb the absorption results. Once the sodium hydroxide is added, it is necessary to cool the solution, then heat the solution to the test temperature; then proceed to bubble the $\mathrm{H}_{2} \mathrm{~S}$. Table 4 shows the results of these tests. At $50{ }^{\circ} \mathrm{C}$ an acceptable absorption time is obtained and there is almost no presence of $\mathrm{Na}_{2} \mathrm{~S} .9 \mathrm{H}_{2} \mathrm{O}$ crystals that affect the suspension and dispersion of gases in the reactor. The solid phase of the reactor is composed almost entirely of $\mathrm{Na}_{2} \mathrm{~S} .5 \mathrm{H}_{2} \mathrm{O}$ and a good absorption of $\mathrm{H}_{2} \mathrm{~S}$ is obtained in the reaction mixture. The choice of $50{ }^{\circ} \mathrm{C}$ is more due to the absorption capacity of $\mathrm{H}_{2} \mathrm{~S}$ with adequate agitation.

The reactant solutions started from the same concentration value of sodium sulfide and sodium sulfhydrate around $2.85 \%$ $\mathrm{Na}_{2} \mathrm{~S} ; 40.58 \% \mathrm{NaHS}$ and $56.57 \% \mathrm{H}_{2} \mathrm{O}$. After 60 minutes of $\mathrm{H}_{2} \mathrm{~S}$ bubbling, $\mathrm{Na}_{2} \mathrm{~S}$ reactants whose temperatures are $50^{\circ} \mathrm{C}$ and $60^{\circ} \mathrm{C}$ which are very close to the value of $1 \%$, while solutions of $70^{\circ} \mathrm{C}$ and $80^{\circ} \mathrm{C}$ are very far from this value (see Fig. 13) were observed.

At 90 minutes, the reactants that are at temperatures of $50^{\circ} \mathrm{C}$ and $60^{\circ} \mathrm{C}$ have reached equilibrium with concentrations close to $0.15 \%$ and remain at this value until 120 minutes, while solutions that are at $70^{\circ} \mathrm{C}$ and $80^{\circ} \mathrm{C}$ continue to fluctuate around $0.4 \%$. These solutions reach equilibrium at 120 minutes with approximately $0.15 \% \mathrm{Na}_{2} \mathrm{~S}$. It is clearly observed that hot solutions greater than $70^{\circ} \mathrm{C}$ have a delay in the progress of the reaction, as a result of the decrease in the solubility of $\mathrm{H}_{2} \mathrm{~S}$ in hot solutions, other works also indicate the decrease in solubility with the increase in temperature in absorption towers [64]. The solubility minimum occurs at higher temperatures. The reasons for these related phenomena are not fully understood, but derive to a large extent from the changes in water structure (breakdown of hydrogen bonding) that take place at increasing temperatures [65]. Up to 30 minutes, the samples of the four tests have almost the same content of $\mathrm{Na}_{2} \mathrm{~S}$ approximately $1.8 \%$. This means that the sodium sulphide in the reactant solution allows the absorption of $\mathrm{H}_{2} \mathrm{~S}$ and when the $\mathrm{Na}_{2} \mathrm{~S}$ content decays, the solubility of the $\mathrm{H}_{2} \mathrm{~S}$ also decays. It is observed that the reactants have absorbed on average 51.8 grams of $\mathrm{H}_{2} \mathrm{~S}$ and according to the content of $\mathrm{Na}_{2} \mathrm{~S}$ it was expected to capture an approximate amount of 57.4 grams of $\mathrm{H}_{2} \mathrm{~S}$. Therefore, almost $90 \%$ of the $\mathrm{H}_{2} \mathrm{~S}$ that has been bubbled was absorbed.

Table 4. Influence of the temperature on the absorption of $\mathrm{H}_{2} \mathrm{~S}$ in the batch reactor.

\begin{tabular}{|c|c|c|c|c|}
\hline \multirow{2}{*}{ Reactants } & \multicolumn{4}{|c|}{ Temperature } \\
\hline & $50{ }^{\circ} \mathrm{C}$ & $60^{\circ} \mathrm{C}$ & $70^{\circ} \mathrm{C}$ & $80{ }^{\circ} \mathrm{C}$ \\
\hline \multicolumn{5}{|c|}{ Preparation of the Reactioning Mixture } \\
\hline NaHS $43.6 \%$ & $4536 \mathrm{~g}$ & $4536 \mathrm{~g}$ & $4536 \mathrm{~g}$ & $4536 \mathrm{~g}$ \\
\hline$[\mathrm{NaHS}]$ & $43.6 \%$ & $43.6 \%$ & $43.6 \%$ & $43.6 \%$ \\
\hline$\left[\mathrm{Na}_{2} \mathrm{~S}\right]$ & $0.32 \%$ & $0.32 \%$ & $0.32 \%$ & $0.32 \%$ \\
\hline \multicolumn{5}{|c|}{ Reactants } \\
\hline $\mathrm{NaOH} \mathrm{50 \%}$ & $120 \mathrm{~g}$ & $120 \mathrm{~g}$ & $120 \mathrm{~g}$ & $120 \mathrm{~g}$ \\
\hline \multicolumn{5}{|c|}{ Balance of materials } \\
\hline$\left[\mathrm{Na}_{2} \mathrm{~S}\right]$ & $2.85 \%$ & $2.83 \%$ & $2.85 \%$ & $2.83 \%$ \\
\hline [NaHS] & $40.58 \%$ & $40.43 \%$ & $40.58 \%$ & $40.53 \%$ \\
\hline$\left[\mathrm{H}_{2} \mathrm{O}\right]$ & $56.57 \%$ & $56.74 \%$ & $56.57 \%$ & $56.74 \%$ \\
\hline Weight of the reactant solution. & $4654 \mathrm{~g}$ & $4653 \mathrm{~g}$ & $4658 \mathrm{~g}$ & $4657 \mathrm{~g}$ \\
\hline $\mathrm{H}_{2} \mathrm{~S}$ & $57.4 \mathrm{~g}$ & $57.4 \mathrm{~g}$ & $57.4 \mathrm{~g}$ & $57.4 \mathrm{~g}$ \\
\hline \multicolumn{5}{|l|}{ Results } \\
\hline Final weight reaction.solution & $4706 \mathrm{~g}$ & $4707 \mathrm{~g}$ & $4713 \mathrm{~g}$ & $4710 \mathrm{~g}$ \\
\hline Amount $\mathrm{H}_{2} \mathrm{~S}$ absorbed & $51 \mathrm{~g}$ & $53 \mathrm{~g}$ & $52 \mathrm{~g}$ & $51 \mathrm{~g}$ \\
\hline \multicolumn{5}{|c|}{ Balance de materiales-calculado } \\
\hline$\left[\mathrm{Na}_{2} \mathrm{~S}\right]$ & $0.14 \%$ & $0.13 \%$ & $0.16 \%$ & $0.18 \%$ \\
\hline$[\mathrm{NaHS}]$ & $43.95 \%$ & $43.79 \%$ & $43.66 \%$ & $43.41 \%$ \\
\hline$\left[\mathrm{H}_{2} \mathrm{O}\right]$ & $55.91 \%$ & $56.05 \%$ & $55.56 \%$ & $56.07 \%$ \\
\hline
\end{tabular}




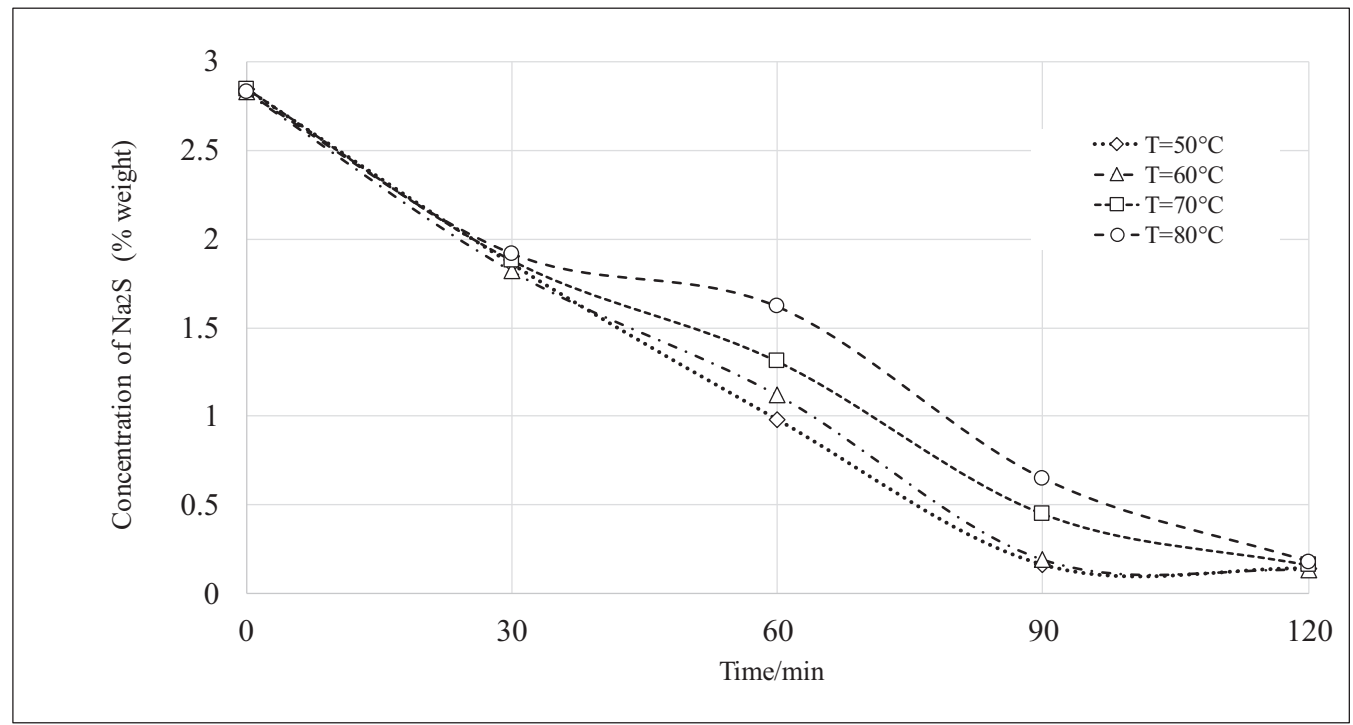

Fig. (13). $\mathrm{Na}_{2} \mathrm{~S}$ concentration profile, influence of temperature in the absorption of $\mathrm{H}_{2} \mathrm{~S}$ : $\mathrm{H}_{2} \mathrm{~S}$ flow $(0.44 \mathrm{~L} / \mathrm{min})$

Table 5. Results of the test of influence of the temperature in the reaction.

\begin{tabular}{|c|c|c|c|}
\hline & Test $\mathbf{N}^{\mathbf{1}}$ & Test $^{\mathbf{0}} \mathbf{2}$ & Test $^{\mathbf{0}} \mathbf{3}$ \\
\hline Mean temperature & $\mathbf{3 0}{ }^{\mathbf{0}} \mathbf{C}$ & $\mathbf{5 0}^{\mathbf{0}} \mathbf{C}$ & $\mathbf{7 0}^{\mathbf{0}} \mathbf{C}$ \\
\hline Presence of $\mathrm{H}_{2} \mathrm{~S}$ & Yes (Until 45 minute- $125 \mathrm{ppm})$ & Yes (from minute 150,85 ppm) & Yes (from minute 135,95 ppm) \\
\hline Total, NaHS 43\% & $\mathbf{4 9 5 2} \mathbf{g}$ & $\mathbf{4 9 7 7} \mathbf{g}$ & $\mathbf{4 9 6 7} \mathbf{g}$ \\
\hline$[\mathrm{NaHS}]$ & $43,75 \%$ & $43,27 \%$ & $41,83 \%$ \\
\hline$\left[\mathrm{Na}_{2} \mathrm{~S}\right]$ & $0,21 \%$ & $0,15 \%$ & $1,76 \%$ \\
\hline$\left[\mathrm{H}_{2} \mathrm{~S}\right]$ & $56,34 \%$ & $56,58 \%$ & $56,41 \%$ \\
\hline
\end{tabular}

\subsection{Influence of Temperature in the Advance of the Reaction}

The influence of temperature on the reaction for the proposed formulation $\left(13.3 \% \mathrm{Na}_{2} \mathrm{~S}, 26.9 \% \mathrm{NaHS}\right.$ and $59.8 \%$ $\mathrm{H}_{2} \mathrm{O}$ ) was studied (Table 5). This reaction medium allows the sodium sulfide crystals to remain in suspension when appropriate agitation is applied. In addition to sodium sulfide, ions react with the absorbed $\mathrm{H}_{2} \mathrm{~S}$ in the middle. After 180 minutes of reaction, the reaction solution shows crystals of sodium sulphide, and in a higher proportion when the reaction mixture is at $30^{\circ} \mathrm{C}$. After 10 minutes of settling, a reactant solution is observed whereby practically $50 \%$ of the reactor volume consists of sodium sulfide crystals. This level of solids in the reactor is unfavorable and affects the agitation as well as in the conversion process.

The reactions at $30^{\circ} \mathrm{C}$ and $50^{\circ} \mathrm{C}$ end before the reactions at $70^{\circ} \mathrm{C}$ end because at lower temperatures the reaction solution absorbs more $\mathrm{H}_{2} \mathrm{~S}$. This effect was expected since at temperatures close to $70^{\circ} \mathrm{C}_{2} \mathrm{~S}$ solubility is lower than at the previous ones. According to the chemical analysis of the product obtained at the temperature of $70^{\circ} \mathrm{C}$, it is observed that it had not exceeded the required concentration (greater than $43 \%$ ), and the analyzer of $\mathrm{H}_{2} \mathrm{~S}$ from minute 150 registered high values of $\mathrm{H}_{2} \mathrm{~S}$ that left the reactor $\left(95 \mathrm{ppm} \mathrm{H}_{2} \mathrm{~S}\right)$. A generation of NaHS of $1023 \mathrm{~g}$ (i.e. $4990 \mathrm{~g} \mathrm{NaHS}$ in the reactor) was expected. However, $4967 \mathrm{~g}$ of NaHS was obtained in the reactor. That is, a difference in weight of $23 \mathrm{~g}$ which means that about $8 \%$ of the initially planned $\mathrm{H}_{2} \mathrm{~S}(275 \mathrm{~g})$ had not been absorbed. On the other hand, the reaction at $30^{\circ} \mathrm{C}$ releases $\mathrm{H}_{2} \mathrm{~S}$ from the reactor from the start of bubbling and the release continues until 60 minutes later, after which the load becomes lighter and the $\mathrm{H}_{2} \mathrm{~S}$ level escaping from the reactor slowly decreases. From the agitation point of view, the high presence of solids in the reaction mixture that is at $30^{\circ} \mathrm{C}$ causes the crystals to deposit in the deflectors of the reactor and vary the final concentration of the obtained product.

Working at temperatures of $30^{\circ} \mathrm{C}$ according to the proposed formulation, problems at the beginning of the reaction due to the adherence of the sodium sulfide crystals on the surface of the reactor that affect the correct agitation of the medium because at this temperature there is a high load of sodium sulfide crystals that represent about $52 \%$ according to the volume of the reactor that affects $\mathrm{H}_{2} \mathrm{~S}$ absorption. The most favorable test is at $50^{\circ} \mathrm{C}$ because no significant amounts of $\mathrm{H}_{2} \mathrm{~S}$ are detected at the beginning of the reaction, but until minute 150 which is where practically all the $\mathrm{Na}_{2} \mathrm{~S}$ has reacted and no more $\mathrm{H}_{2} \mathrm{~S}$ is absorbed. At a temperature of $50^{\circ} \mathrm{C}$, the amount obtained differs from what is expected by 11 g. In Fig. (14) the $\mathrm{pH}$ profile is observed with respect to each reactor temperature and the delay in the completion of the reaction when tested at $70^{\circ} \mathrm{C}$ is clearly seen. 


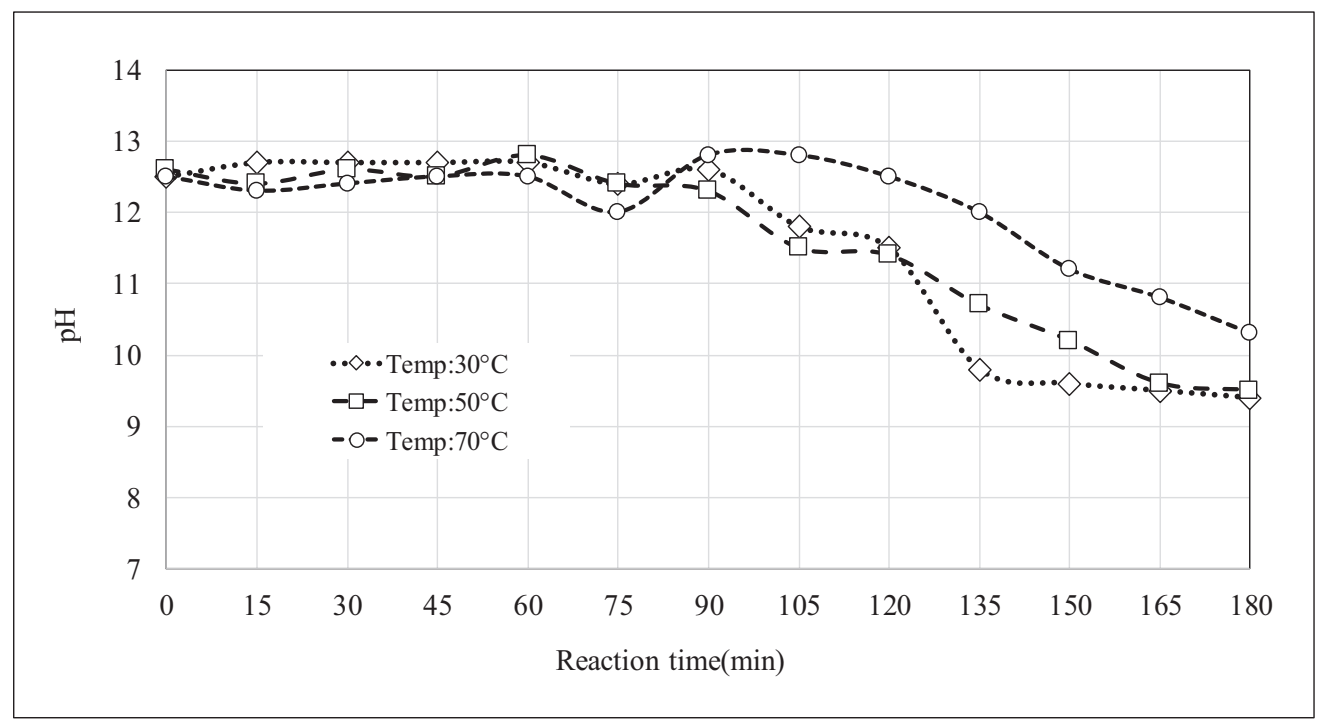

Fig. (14). $\mathrm{pH}$ profile in the advance of the reaction: Influence of temperature.

This work was carried out in the Reactivos Nacionales S.A, in order to solve a serious environmental problem related to hydrogen sulfide produced as a byproduct in the production process of dithiophosphoric acids. The problem was solved by producing NaHS, which the company can commercialize. Next we show the dimensioning of the industrial reactor.

\subsection{Chemical-industrial Reactor Design}

The stirred tank reactor is the most frequently used in process industries [66] to bring about an excellent solid-liquid, gas-liquid or gas-solid-liquid contact. The adequate degree of suspension of solid particles mean homogenization of slurry so formed or a near homogenization such that the suspension ensures uniform process conditions leading to predictable results. And the adequate degree of mixing is the required degree of turbulence which minimizes the mas transfer resistances [67]. For the industrial manufacture of sodium sulfhydrate in aqueous solution, the three-phase reactor has the following functions:

- To ensure the adequate contact of the reactants to obtain NaHS: $\mathrm{H}_{2} \mathrm{~S}$ (gas) - sodium sulfide crystals(solid) - reaction solution (liquid).

- To provide sufficient contact time between substances.

- To allow temperature conditions and composition of the reactants so that the chemical reaction develops at the desired speed.

The hydrodynamics of the fluids and the geometrical configuration of the reactors are key to understanding the mixing phenomena. The geometric configuration is so important that the processes can be considered of specific geometry. The turbine of discs with six flat blades for the systems of agitation with radial flow was developed from the studies of Rushton and is considered like a geometric configuration of reference [68]. For that reason, this configuration has been used for the present study. The 6-blade Rushton disc turbine was shown to be the best impeller over a wide range of gas flow rates for dispersing both solids and gases simultaneously [69].

\subsubsection{Dimensioning the Sparger}

The sparger is an important element of the reactor. Its design should allow easy cleaning of the device. Inside the sparger, sodium sulfide crystals are deposited from the reaction mixture when the $\mathrm{H}_{2} \mathrm{~S}$ gas does not enter the reactor. Fig. (15) shows the cross section of the lower part of the reactor, where the agitator is installed, and (Fig. 16) shows the dimensions and capacity of the industrial reactor, based on the correlations shown in Fig. (6c) [42, 46], as well as the Rushton turbine of stainless steel. If it becomes clogged, it must be cleaned on the outside with a stream of hot water to dissolve the crystals inside. The sparger provided for this application consists of a straight tube of $1 \frac{1 / 2}{2}$ "diameter Schedule 40, the material is made of AISI 316 stainless steel. The sparger is provided with three holes of 0.75 inches of diameter, through sparger the $\mathrm{H}_{2} \mathrm{~S}$ bubbles are discharged near the impeller. The location of the sparger is important and is related to the interfacial area (bubble size). In the design of the reactor, the sparger has been placed in favor of flow current for both pilot and industrial tests. The main problem that arises in the design of gas-liquid reactors is the correct evaluation of the interfacial area, a magnitude for which there are no general methods of estimation and which suppose the greatest difficulty in scale changes. Most researchers have found that the specific interfacial area in a bubbling tank is related to gas surface velocity and the power supplied to the dispersion (per unit volume). Molina and collaborators analyze the influence of the variables of operation in the region of low intensities of agitation, on the interfacial area in cylindrical tanks where the disposition of the sparger is modified so that the gas bubbles in favor and against the flow currents [70]. 


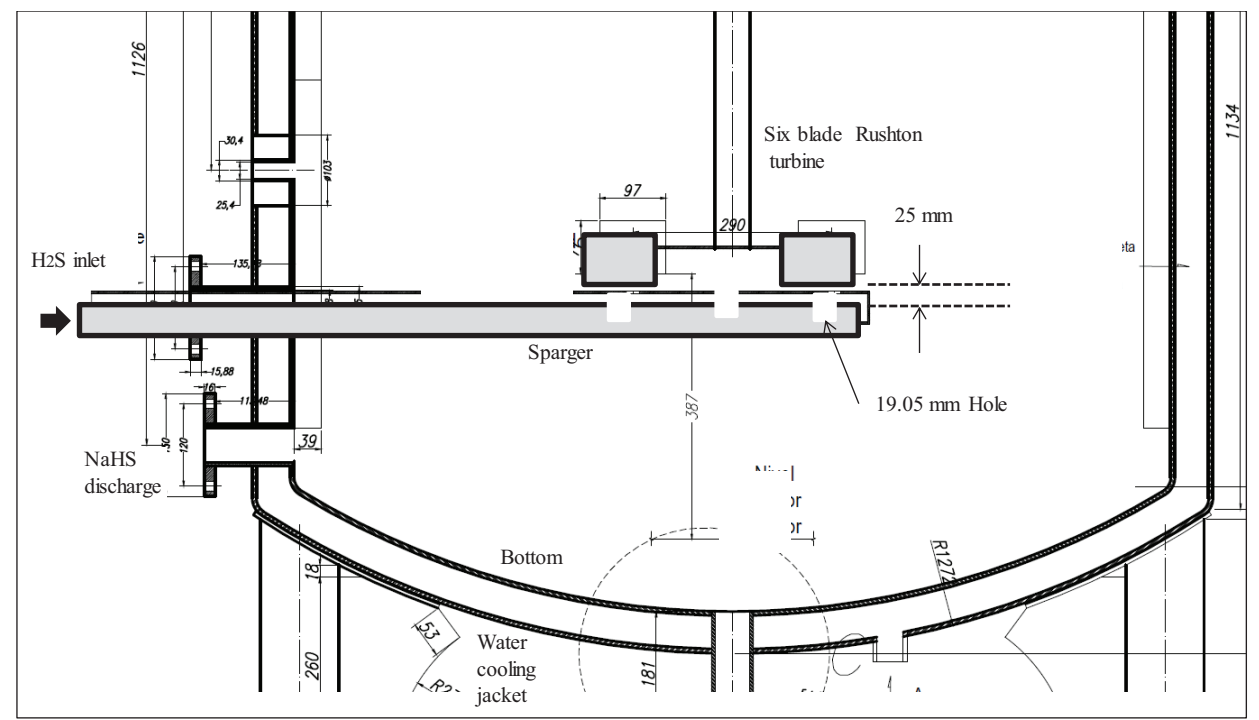

Fig. (15). Position of the bubbler in the industrial reactor.

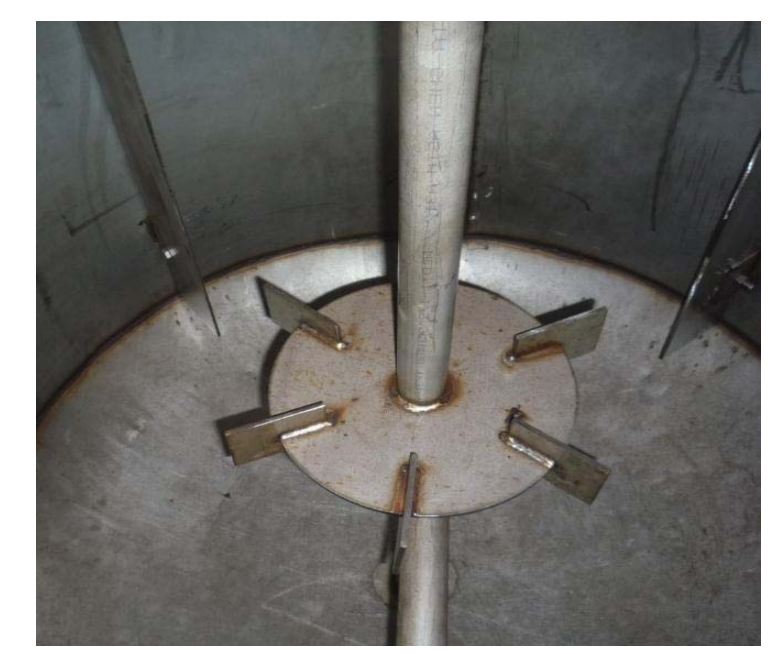

Dimensions (mm)

$$
\begin{array}{r}
\mathrm{D}_{\mathrm{t}}=1.16 \mathrm{~m} \\
\mathrm{Da}=0.387 \\
\mathrm{H}=1.16 \mathrm{~m} \\
\mathrm{Z}=0.387 \\
\mathrm{D} \text { D }=0.290 \mathrm{~m} \\
\mathrm{~B}=0.077 \\
\mathrm{I}=0.097 \\
\mathrm{~W}=0.039 \mathrm{~m} \\
\text { Vol. }=1.226 \mathrm{~m} 3
\end{array}
$$

Fig. (16). Photographic view of the interior of the industrial reactor: Rushton turbine.

\subsubsection{Reactor Temperature Control System}

The objective of controlling the temperature in the reactor is to achieve an adequate conversion in the formation of the product and to keep the system operating around the specified conditions. Two stages take place in the reactor:

- $\quad$ Product training

- Heat removal from the reactor through the cooling jacket

The reagent $\left(\mathrm{H}_{2} \mathrm{~S}\right)$ entering the reaction with sodium sulfide generates heat and heats the system. Temperature is the variable to control, although the most important for the production of NaHS is to control the concentration of the species that are formed in the reactor.

A strict control of the minimum temperature $\left(50^{\circ} \mathrm{C}\right)$ of the
NaHS reactor is essential to avoid the formation of $\mathrm{Na}_{2} \mathrm{~S} .9 \mathrm{H}_{2} \mathrm{O}$ crystals that can cause problems. Controlling the temperature below $55^{\circ} \mathrm{C}$ will allow maintaining a good solubility of the $\mathrm{H}_{2} \mathrm{~S}$ in the reaction solution and thus avoid losses of $\mathrm{H}_{2} \mathrm{~S}$ outside the reactor.

\subsubsection{Thermostat}

The temperature controller is an electronic device that receives the signal from the sensor, and transforms it into temperature values according to the algorithms established for each type of sensor. The controller sends an electrical signal to the final control element (water valve) when comparing the value of the process with the control value using the control mode set. The driver used is of the brand Autonics, Model TZ4M. The type of control that can be done with this device are ON-OFF, P, PI, PD, PIDF and PIDS. For our case, the ONOFF basic mode was used (Fig. 17). 


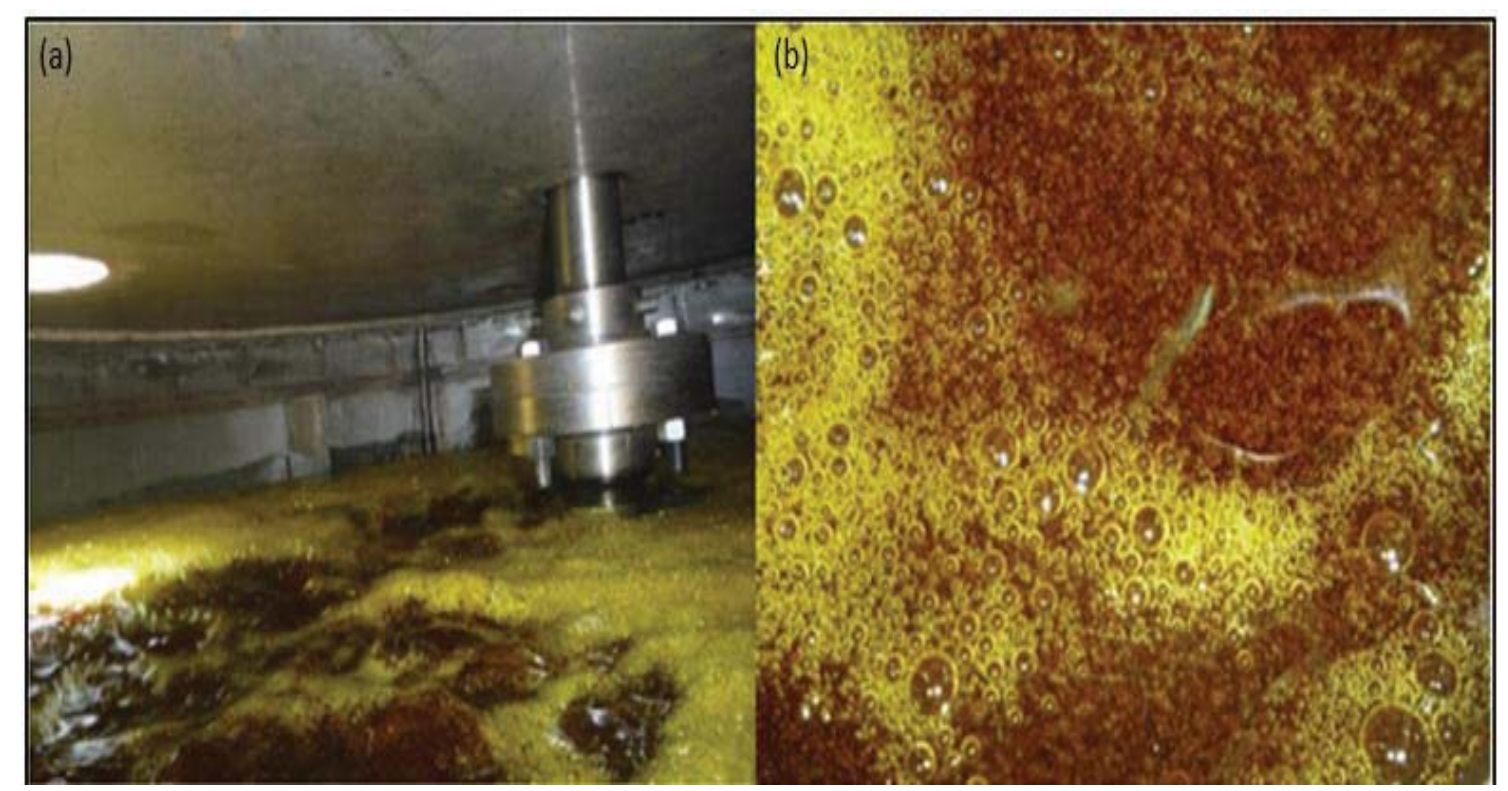

Fig. (17). Photographic view of the bubbling process inside the industrial reactor: (a) Agitator, (b) Foam formation: Reactivos Nacionales S.A Plant, Lima Peru.

\subsubsection{Temperature Sensor}

The temperature sensor installed in the reactor is a threewire Pt100 sensor, whose measuring range ranges from $-100{ }^{\circ} \mathrm{C}$ to $200{ }^{\circ} \mathrm{C}, 6$ " bulb length, $1 / 4$ " bulb diameter, aluminum head.

\subsubsection{Control Valve}

The control valve used is a full-pass valve with a diameter of 1 ", sufficient for the passage of cooling water with a maximum flow of $6.02 \mathrm{~m}^{3} / \mathrm{h}$.

\subsubsection{Control Mode}

The ON-OFF mode is the one used for the temperature control of the reactor, this control is the most basic and efficient enough for our purpose. The equipment of the TZ4M controller of the AUTONICS brand is configured in such a way that:

- It turns on when PV (process value) is less than SV (control value) $\left(53{ }^{\circ} \mathrm{C}\right)$

- It turn off when PV is greater than $\mathrm{SV}\left(53^{\circ} \mathrm{C}\right)$.

\subsubsection{Balance and Stoichiometry of the Reaction: Industrial Essay}

As in the pilot tests, for the industrial tests, it has been determined that the reaction medium will be formed initially of $43 \%$ sodium sulfhydrate concentrated solutions (liquid solution at temperatures higher than $20^{\circ} \mathrm{C}$ ). In this medium, the sodium sulfide $\left(\mathrm{Na}_{2} \mathrm{~S} .5 \mathrm{H}_{2} \mathrm{O}\right)$ crystals will form when stoichiometric amounts of $\mathrm{NaHS}$ and $\mathrm{NaOH}$ react. According to preliminary work at the pilot level it has been confirmed that one of the best proportions (of sodium sulfide, sodium sulfhydrate, and water) in the reaction mixture should start from a weight ratio of $43 \% \mathrm{NaHS} / 50 \% \mathrm{NaOH}=6.24$ and a reaction mixture of overall percentage composition as follows: $13.3 \% \mathrm{Na}_{2} \mathrm{~S}, 26.9 \%$
$\mathrm{NaHS}$ and $59.8 \% \mathrm{H}_{2} \mathrm{O}$. All the industrial tests will be carried out starting with a $50 \%$ sodium hydroxide industrial grade and sodium sulfhydrate greater than $43 \%$ (with contents less than $0.4 \% \mathrm{Na}_{2} \mathrm{~S}$ ) in the commercial grade that is available at the plant.

For the purposes of this calculation, the NaHS available for the first test has a concentration of $43.2 \%$ (with contents less than $0.1 \%$ of $\mathrm{Na}_{2} \mathrm{~S}$ ). Formation of $\mathrm{Na}_{2} \mathrm{~S}$, taking into account (Eq. 7), starting with $212 \mathrm{~kg}$ of $50 \% \mathrm{NaOH}$. This equation allows to determine the requirements of reactants and reaction media for the formation of sodium sulfide. NaHS requirement at $43 \%$ for the formation of $\mathrm{Na}_{2} \mathrm{~S}$ :

$\mathrm{M}_{\mathrm{NaHS}}=\frac{0.5 \cdot 212 \mathrm{~kg} \mathrm{NaOH}}{39.9\left(\frac{\mathrm{g} \mathrm{NaOH}}{\mathrm{mol} \mathrm{NaOH}}\right)} \cdot 56.063\left(\frac{\mathrm{g} \mathrm{NaHS}}{\mathrm{mol} \mathrm{NaHS}}\right)\left(\frac{1 \mathrm{~mol} \mathrm{NaHS}}{1 \mathrm{~mol} \mathrm{NaOH}}\right)$
$\mathrm{M}_{\mathrm{NaHS}}=148.6 \mathrm{~kg}, \mathrm{M}_{\mathrm{H} 2 \mathrm{O}}=195.0 \mathrm{~kg}$ (water that accompanies sodium sulfhydrate), $\mathrm{M}_{\mathrm{Na} 2 \mathrm{~S}}=0.3 \mathrm{~kg}$ (Sodium sulphide that accompanies sodium sulfhydrate): $\mathrm{M}_{\mathrm{NaHS}, 43,2 \%}=$ $343.9 \mathrm{~kg}$

\section{$\mathrm{Na}_{2} \mathrm{~S}$ generation:}

$$
\begin{aligned}
& \mathrm{M}_{\mathrm{NaHS}}=\frac{0.5 \cdot 212 \mathrm{~kg} \mathrm{NaOH}}{39.9\left(\frac{\mathrm{g} \mathrm{NaOH}}{\mathrm{mol} \mathrm{NaOH}}\right)} \cdot 78.045\left(\frac{\mathrm{g} \mathrm{Na} 2 \mathrm{~S}}{\mathrm{~mol} \mathrm{Na} \mathrm{N}_{2} \mathrm{~S}}\right)\left(\frac{1 \mathrm{~mol} \mathrm{Na}_{2} \mathrm{~S}}{1 \mathrm{~mol} \mathrm{NaOH}}\right) \\
& \mathrm{M}_{\mathrm{Na} 2 \mathrm{~S}}=206.8 \mathrm{~kg}
\end{aligned}
$$

\section{$\mathrm{H}_{2} \mathrm{O}$ generation:}

$$
\begin{aligned}
& \mathrm{M}_{\mathrm{H} 2 \mathrm{O}}=\frac{0.5 \cdot 212 \mathrm{~kg} \mathrm{NaOH}}{39.9\left(\frac{\mathrm{g} \mathrm{NaOH}}{\mathrm{mol} \mathrm{NaOH}}\right)} \cdot 18.015\left(\frac{\mathrm{g} \mathrm{H}_{2} \mathrm{O}}{\mathrm{mol} \mathrm{H}_{2} \mathrm{O}}\right)\left(\frac{1 \mathrm{~mol} \mathrm{H}_{2} \mathrm{O}}{1 \mathrm{~mol} \mathrm{NaOH}}\right) \\
& \mathrm{M}_{\mathrm{H} 20}=47.7 \mathrm{~kg} .
\end{aligned}
$$


Water from $50 \%$ sodium hydroxide (considering that the content of carbonates and other substances are less than $0.1 \%$ ) is: $\mathrm{M}_{\mathrm{H} 2 \mathrm{O}}=106 \mathrm{~kg}$ (of sodium hydroxide).

\section{NaHS Requirement $43.2 \%$ as Reactant and Reactant Medium}

The requirement of NaHS at $43.2 \%$ as reactant and reactant means is $1322 \mathrm{~kg}$ of NaHS $43.2 \%$ of which $978.9 \mathrm{~kg}$, will serve as a reaction medium that will promote the suspension of the sodium sulfide crystals formed. In $978.9 \mathrm{~kg}$ of $\mathrm{NaHS}$ $43.2 \%$ it has as: $\mathrm{NaHS}=422.9 \mathrm{~kg}, \mathrm{Na}_{2} \mathrm{~S}=1 \mathrm{~kg}$ and $\mathrm{H}_{2} \mathrm{O}=555$ $\mathrm{kg}$.

\section{Adjustment of the Reaction Mixture}

Soft water is added for the NaHS dilution in order to correct the NaHS concentration to $43.5 \%$. The water for the compensation and readjustment of the concentration of the reaction mixture is: $\mathrm{M}_{\mathrm{H} 2 \mathrm{O}}=34 \mathrm{~kg}$

The sum of all the contributions and the chemical species present in the reaction mixture corresponding to the sodium sulfide formation step makes a total of $1568.9 \mathrm{~kg}$ for a reactant solution with the following weight percentage composition: $\mathrm{M}_{\mathrm{Na} 2 \mathrm{~S}}=208.2 \mathrm{~kg}(13.27 \%), \mathrm{M}_{\mathrm{NaHS}}=422.9 \mathrm{~kg}(26.95 \%), \mathrm{M}_{\mathrm{H} 2 \mathrm{O}}=$ $937.8 \mathrm{~kg}(59.78 \%), \mathrm{M}$ total $=1569 \mathrm{~kg}(100 \%)$. It has experimentally been verified that under this formulation and at $50{ }^{\circ} \mathrm{C}$, about $40 \%$ by volume of solids formed by sodium sulfide crystals and $60 \%$ of a liquid phase are obtained. The mixture possesses good properties for agitation. The content of solids (sodium sulfide crystals) at $50{ }^{\circ} \mathrm{C}$ is $22.16 \%$ by weight. Weight of the solid phase: $347 \mathrm{~kg}$, Weight liquid phase: 1220 $\mathrm{kg}$.

Initial composition of the chemical species in aqueous phase (reactant solution) at $50{ }^{\circ} \mathrm{C}$ is: $3.6 \% \mathrm{Na}_{2} \mathrm{~S}, 35.0 \% \mathrm{NaHS}$, $61.0 \% \mathrm{H}_{2} \mathrm{O}$.

\section{Generation of NaHS: According to (Eq.8)}

For the conversion of all the sodium sulfide content of the reaction mixture the amount of $\mathrm{H}_{2} \mathrm{~S}$ required is:

$$
\mathrm{MH} \mathrm{H}_{2} \mathrm{~S}=\frac{208,2 \mathrm{~kg} \mathrm{Na} a_{2} \mathrm{~S}}{78,045\left(\frac{\mathrm{g} \mathrm{Na} 2 \mathrm{~S}}{\mathrm{~mol} \mathrm{Na} a_{2} \mathrm{~S}}\right)} \cdot 56,063\left(\frac{\mathrm{g} \mathrm{NaHS}}{\mathrm{mol} \mathrm{NaHS}}\right)\left(\frac{2 \mathrm{~mol} \mathrm{NaHS}}{1 \mathrm{~mol} \mathrm{Na}_{2} \mathrm{~S}}\right)
$$

$\mathrm{M}_{\mathrm{NaHS}}=299.1 \mathrm{~kg}$ of which $149.5 \mathrm{~kg}$ is generated as final product and the rest is reincorporated into the reaction medium (NaHS $43 \%$ ): $\mathrm{M}_{\mathrm{NaHS}}=149.5 \mathrm{~kg}$. From the total balance of the reaction mixture and finishing the reaction there is a total mass of: $\mathrm{M}$ total $=1659.8 \mathrm{~kg}$

\subsection{Determination of Critical Speed $\left(\mathrm{N}_{\mathrm{JS}}\right)$ for the Suspension of $\mathrm{Na}_{2} \mathrm{~S}$ Crystals in a NaHS Solution for the Pilot Reactor and Industrial Reactor}

Solids suspension applications require accurate specification of the impeller speed because these operations are power intensive. These stirred tanks are usually operated at the just suspended speed, $\mathrm{Njs}$, which is the impeller speed at which no particles remain stationary at the bottom of the tank for more than 1 or $2 \mathrm{~s}$ [71 - 76], and five states of suspension were observed that occur in solid liquid agitation with respect to the speed of the agitator $(\mathrm{N})$. When the agitator speed reaches the $\mathrm{Njs}$ it can be said that a complete suspension is found [77]. The critical impeller speed for solids suspension $(\mathrm{Njs})$, also has been studied in gas inducing mechanically agitated contactors fitted with two impellers by Saravanan et al., the study shows various stages of the solid phase during the process of solid suspension [78]. A critical analysis of this correlation (Eq. 25) can be consulted in [72]. The geometric parameters that affect $\mathrm{Njs}$ are impeller diameter, tank diameter, off-bottom clearance of the impeller, type of impeller, off-bottom clearance of baffles and shape of the tank bottom [72, 79]. S is a function of impeller type, impeller diameter and off-bottom clearance [72]. $\mathrm{S}$ is very sensitive to geometry [72], but also depends on the type of the particle $[72,80]$. The amount of suspend solids as a function of impeller speed depends on the presence of fine particles in the suspended material. The more fines are present, the higher the amount of suspended solids are result [81]. For the design of the critical speed of suspension of the industrial reactor it is necessary to know the correlation constant of Zwieteering (S), which is visually characterized [73]. For this, the characteristics of the suspension in the pilot reactor were observed considering (Eq. 25).

$$
N_{J S}=S \cdot v^{0,1} \cdot\left[\frac{g \cdot(\rho s-\rho l)}{\rho l}\right]^{0,45} \cdot X^{0,13} \cdot d p^{0,2} \cdot D^{-0,85}
$$

For the reaction mixture (see 3.5): $v=0.00488 \mathrm{~m}^{2} / \mathrm{s}$ (NaHS kinematic viscosity $43 \%$ at $50{ }^{\circ} \mathrm{C}$ ), g= $9.806 \mathrm{~m} / \mathrm{s}^{2}$ (Gravity), $\rho \mathrm{l}=1.28 \mathrm{~kg} / \mathrm{m}^{3}$ (NaHS density $43 \%$ at $50{ }^{\circ} \mathrm{C}$ ), $\rho \mathrm{s}=1.58 \mathrm{~kg} / \mathrm{m}^{3}$ (Density of solid $\mathrm{Na}_{2} \mathrm{~S} .5 \mathrm{H}_{2} \mathrm{O}$ ), $\mathrm{X}=0.22$ concentration of solids (weight ratio), $\mathrm{dp}=1500 \mu \mathrm{m}$ (particle diameter), $\mathrm{D}=0.056 \mathrm{~m}$ (agitator diameter). With the pilot reactor, different speeds have been tested and it has been concluded that for a speed of $600 \mathrm{rpm}(10 \mathrm{rev} / \mathrm{s})$ an adequate suspension of the crystals is achieved.

The vortex on the agitation surface and the distribution of particles is not appreciated in the solution. It is homogeneous, even from $550 \mathrm{rpm}$. While $600 \mathrm{rpm}(10 \mathrm{rev} / \mathrm{s})$ is the critical suspension rate $(\mathrm{Njs})$ in the multiphase reactor, the correlation constant "S" has a value of 4.516. The critical velocity for the solids suspension $(\mathrm{Njsg}$ ) in the Gas-Liquid-Solid reactor is calculated according to (Eq. 26) [82].

$$
\Delta N_{j s}=N_{j s g}-N_{j s}=k . Q_{g}
$$

Constant $\mathrm{k}$ was determined by [83] whose value is 0.94 . Where: $\mathrm{Njs}=10 \mathrm{rev} / \mathrm{s}$ (Critical speed for the dispersion of gases in an S-L reactor) and $\mathrm{Qg}=0.41 \mathrm{vvm}$ (gas flow). Applying (Eq. 26), the minimum value for Njsg is $623.12 \mathrm{rpm}$ (10.39 rev / s). For the industrial reactor, the critical speed $(\mathrm{Njs})$ for the suspension of $\mathrm{Na}_{2} \mathrm{~S}$ crystals in a NaHS solution is evaluated taking into account: $\mathrm{S}=4.516, \mathrm{D}=0.387 \mathrm{~m}$ (diameter of the agitator), and the other parameters of the (Eq. 25) are the same as mentioned above: it is $58.06 \mathrm{rpm}(0.967 \mathrm{rev}$ / sec). For an aeration rate of $0.2 \mathrm{vvm}$ and with Eq. 26, the minimum critical velocity (Njsg) for the suspension of solids in 
the industrial reactor results in $69.34 \mathrm{rpm}(1.16 \mathrm{rev} / \mathrm{sec})$. Finally, the conditions for NaHS production at the industrial level are established as follows: Composition mentioned above, temperature of $50^{\circ} \mathrm{C}$, agitation speed of $80 \mathrm{rpm}$, and a luxury of

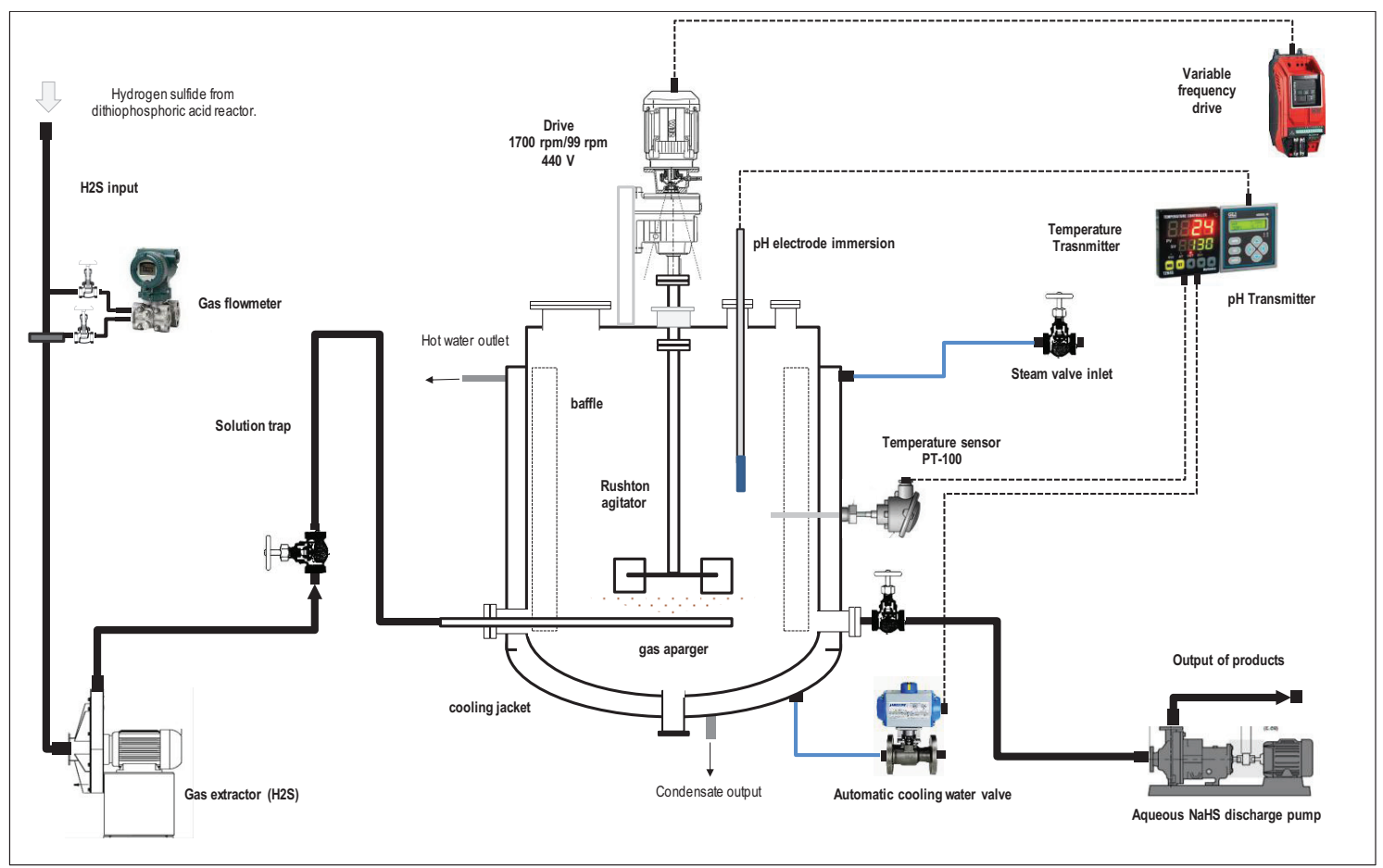

Fig. (18). Instrumentation diagram of the industrial reactor (Reactivos Nacionales S.A).

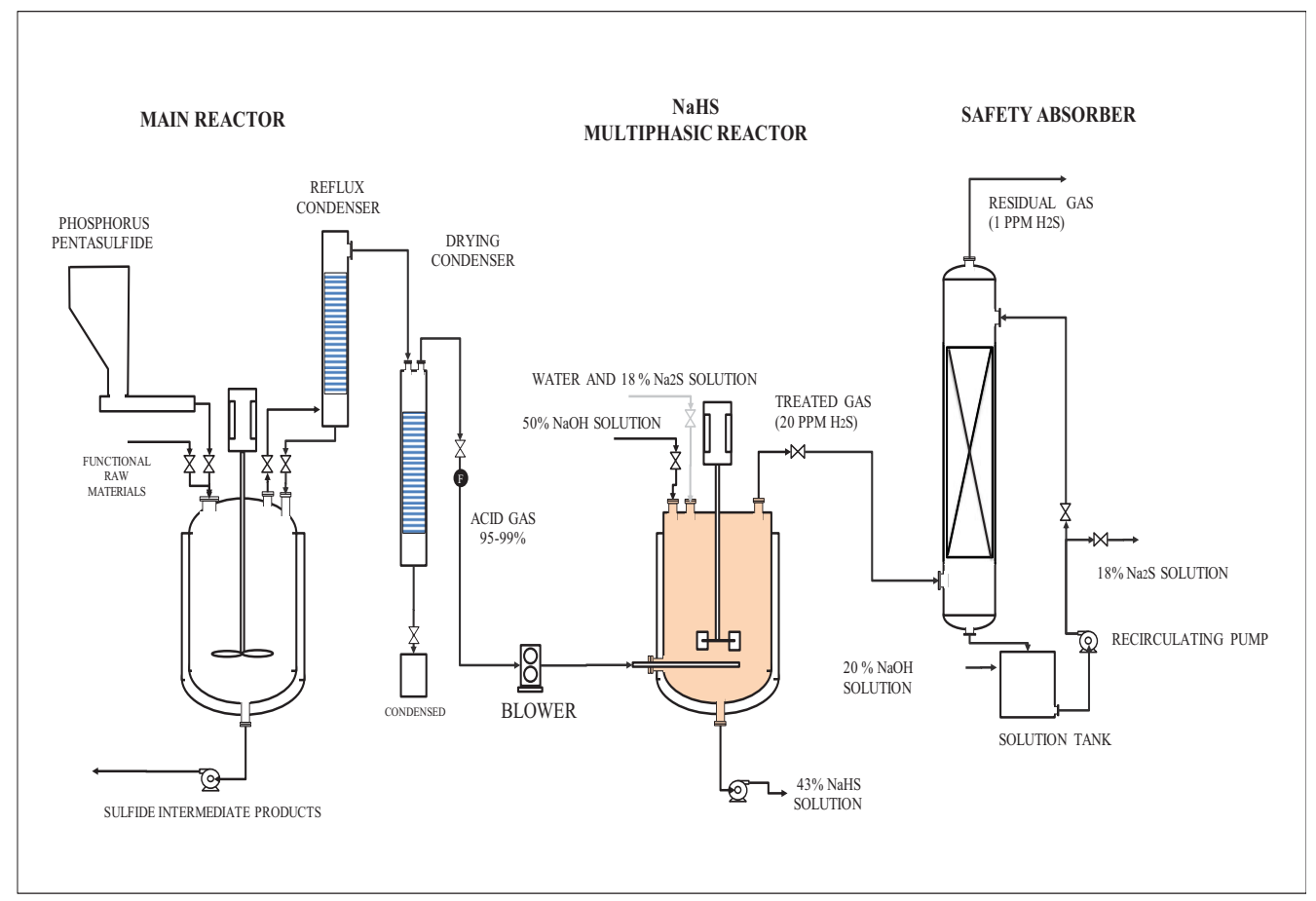

Fig. (19). NaHS production reactor integrated to the main process (Reactivos Nacionales S.A). 


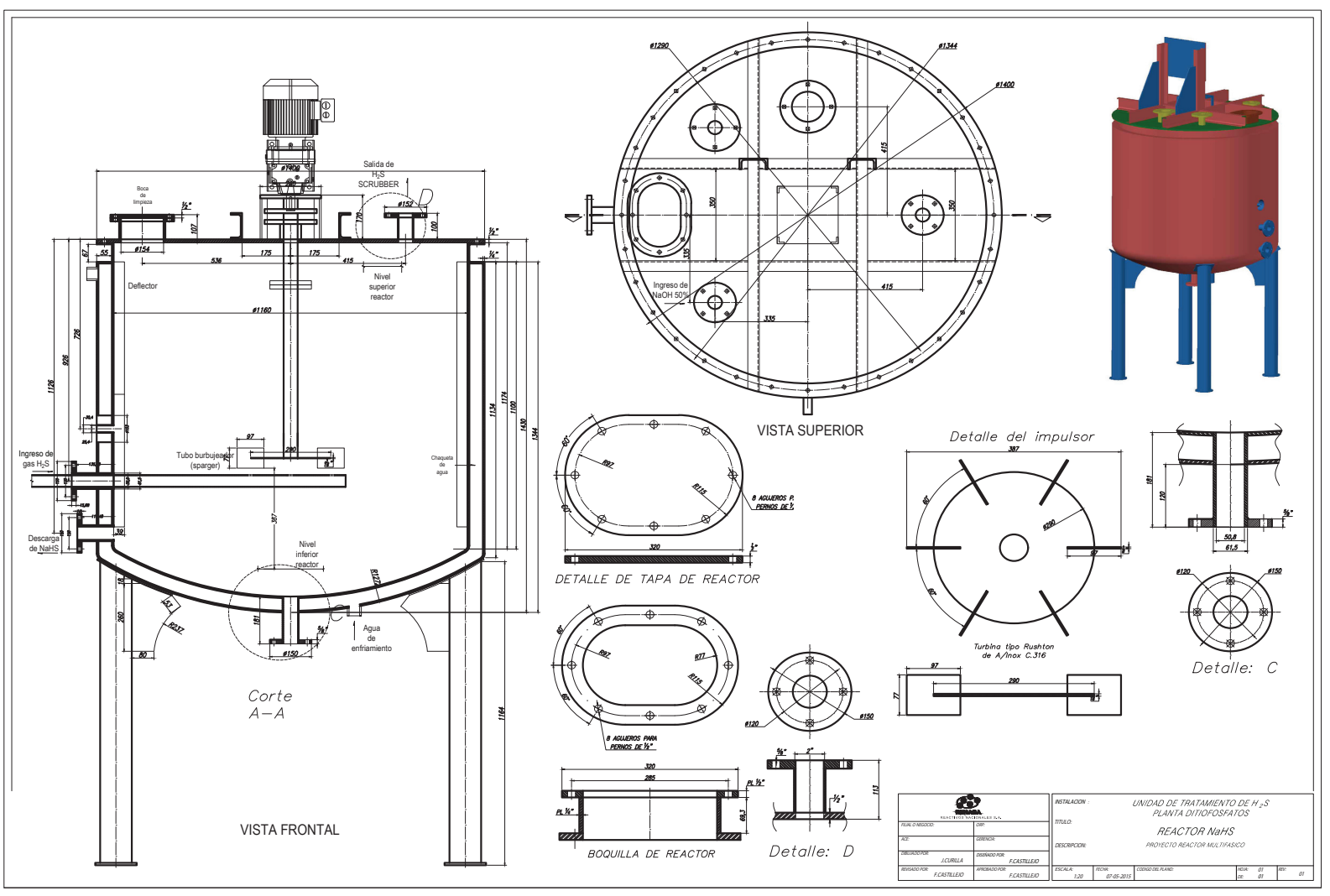

Fig. (20). Detailed plan of the NaHS reactor, for the dithiophosphate acid plant of the company Reactivos Nacionales. S.A.

$\mathrm{H}_{2} \mathrm{~S}$ gas of $0.2 \mathrm{vvm}$ (for 4-hour reaction) which is on average that a stable production of $\mathrm{H}_{2} \mathrm{~S}$ is recorded, although the $\mathrm{H}_{2} \mathrm{~S}$ is generated in the ADTF reactor for 6 hours until it is completely extinguished, and the cooling water flow of the system is 1930 $\mathrm{L}(8.04 \mathrm{~L} / \mathrm{min})$. The calculations of this part are not presented. Figs. (17-20) show the internal part of the reactor in full operation, the instrumentation diagram of the industrial reactor, the integration of the reactor within the process of production of dithiophosphoric acids, and the complete design of the reactor respectively.

The gas hold-up (Eg) corresponding to a gas flow of 0.2 vvm, at a temperature of the NaHS solution $43 \%$ of $50{ }^{\circ} \mathrm{C}, \mathrm{pH}$ of 8.5, where the absorption of $\mathrm{H}_{2} \mathrm{~S}$ has decayed, therefore the gas It retains in the reaction mixture and it is observed that bubbles and foams are produced on the surface. The maximum volume displaced is $1397 \mathrm{~L}$ (without considering the foam mattress). The volume of the aqueous solution of NaHS with agitation and without gas flow is 1285 liters. Therefore the Eg [84] is: Eg (hold-up) $=(1397-1285) / 1397=0.0801$.

When the $\mathrm{pH}$ is greater than 11 , there are few $\mathrm{H}_{2} \mathrm{~S}$ bubbles and the foam mattress is not observed. The maximum displaced volume is $1397 \mathrm{~L}$, at this point the $\mathrm{H}_{2} \mathrm{~S}$ bubbles collapse and are absorbed in the reaction mixture, and no gas retention is observed. When the industrial reactor with an impeller diameter of $0.387 \mathrm{~m}$ and agitator speed of $1.33 \mathrm{rev} / \mathrm{s}$, works with the $43 \% \mathrm{NaHS}$ solution at $50^{\circ} \mathrm{C}$, the viscosity and density of the solution are 0.00624 Pa.s and $1280 \mathrm{~kg} / \mathrm{m}^{3}$ respectively. The value of the Reynolds Number $\left(\mathrm{NRe}=\mathrm{ND}^{2} \rho\right.$ / $\mu$ ) $[85,86]$ is 40860 . For a Rushton type impeller with W / D $=1 / 5$, graphically $[85,86]$ the value of the power number of 5 .

The power number $(\mathrm{Np})$ has not been directly measured, however the power consumption of the agitator motor is 1230 Watts, which allows to maintain an adequate agitation, suspension of the crystals and dispersion of the $\mathrm{H}_{2} \mathrm{~S}$ bubbles, for a reaction mixture of $1644 \mathrm{~kg}$. In all forms of the reaction mixture (single phase, two phase and three phase) there is no significant change in power consumption. However, there is a major change in the adjustment of the axial seals of the (packed gland) agitator.

\section{CONCLUSION}

In this study, the synthesis of sodium sulfhydrate was carried out from hydrogen sulphide, which is a highly toxic gas and a by-product of the dithiophosphoric acids production process in the Reactivos Nacionales S.A. Company.

- A recovery method has been established and implemented that allowed obtaining sodium sulfhydrate with concentrations higher than $43 \%$, in a semicontinuous form and at temperatures ranging from $50{ }^{\circ} \mathrm{C}$ to $55^{\circ} \mathrm{C}$, with an average temperature of 52.5 ${ }^{\circ} \mathrm{C}$. The temperatures reached are much lower than the temperatures of recovery technologies currently available in the market. 
- It is possible to produce aqueous solutions of sodium sulfhydrate from Gas-Liquid-Solid reactions. The conversion of hydrogen sulphide into sodium sulfhydrate was carried out in a stirred multi-phase reactor at $700 \mathrm{rpm}$, which allows the solids to be kept in suspension, which are mainly made up of sodium sulfide crystals $\left(\mathrm{Na}_{2} \mathrm{~S} .5 \mathrm{H}_{2} \mathrm{O}\right)$.

- According to the tests carried out, the conversions of $\mathrm{H}_{2} \mathrm{~S}$ in NaHS obtained in the multiphase reactor are greater than $90 \%$.

- From sodium hydroxide at $50 \%$ of commercial grade, $43 \%$ sodium sulfhydrates have been obtained, chemical Eqs. (2-4, 8 and 13) explain the process. The reaction medium that promotes the conversion is formed by an aqueous solution of $\mathrm{NaHS}$ and $\mathrm{Na}_{2} \mathrm{~S}$ that allows the suspension of the sodium sulfide crystals and the contact with the $\mathrm{H}_{2} \mathrm{~S}$ gas in a multiphase reactor.

- Temperature is a critical parameter in the process. At temperatures below $30^{\circ} \mathrm{C}$, the presence of $\mathrm{Na}_{2} \mathrm{~S} .9 \mathrm{H}_{2} \mathrm{O}$ crystals affects gas dispersion, reactor hydrodynamics, crystal distribution, heat transfer and absorption of $\mathrm{H}_{2} \mathrm{~S}$ in the multiphase reactor. At temperatures above $60^{\circ} \mathrm{C}$, a low absorption of hydrogen sulphide in the reaction medium is registered and consequently a slow conversion of $\mathrm{Na}_{2} \mathrm{~S}$ into NaHS.

- It has been found in this investigation that the main drawback for the manufacture of aqueous solutions of sodium sulfhydrate at concentrations higher than $40 \%$ by weight, starting directly from sodium hydroxide, is the formation of sodium sulfide crystals $\left(\mathrm{Na}_{2} \mathrm{~S} .5 \mathrm{H}_{2} \mathrm{O}\right.$, $\mathrm{Na}_{2} \mathrm{~S} .9 \mathrm{H}_{2} \mathrm{O}$ ) due to its low solubility of these crystals, it is not possible to obtain sodium sulfhydrate safely and efficiently in stirred chemical reactors.

- To obtain $43 \%$ NaHS, sodium sulphide and water with percentages of $34 \%$ and $56 \%$ respectively are necessary. At temperatures higher than $50{ }^{\circ} \mathrm{C}$, two phases could be obtained, comprising an aqueous $\mathrm{Na}_{2} \mathrm{~S}$ solution and $\mathrm{Na}_{2} \mathrm{~S} .5 \mathrm{H}_{2} \mathrm{O}$ (C2) crystals. At lower temperatures, the combination of $\mathrm{Na}_{2} \mathrm{~S} .5 \mathrm{H}_{2} \mathrm{O}(\mathrm{C} 2)$ and $\mathrm{Na}_{2} \mathrm{~S} .9 \mathrm{H}_{2} \mathrm{O}(\mathrm{C} 1)$ crystals will appear, starting the solidification of the system, which is a serious problem.

- The agitation speed in the multiphase reactors (pilot and industrial level) studied allows to adequately disperse the gases and maintain the suspension of the sodium sulfide crystals in the reaction mixture to favor the chemical conversion. The best agitation speeds for the reactants established in this study are: $700 \mathrm{rpm}$ for the pilot reactor and $80 \mathrm{rpm}$ for the industrial reactor.

- The results obtained experimentally in the pilot reactor of 5 liters, provided sufficient information to size the reactor of the industrial type of 1300 liters of capacity, which is appropriate for the requirements of treatment of the residual current of $\mathrm{H}_{2} \mathrm{~S}$ produced in the manufacturing process of dithiophosphoric acids.

- The proposed process has been integrated into the dithiophosphoric acids manufacturing plant, where it has been possible to recover more than $95 \%$ of the hydrogen sulfide in the form of NaHS $43 \%$ (around $90 \%$ of $\mathrm{H}_{2} \mathrm{~S}$ in the multiphase reactor and plus $5 \%$ in the safety absorber).

\section{AVAILABILITY OF DATA AND MATERIALS}

Not applicable.

\section{FUNDING}

The study was funded by Reactivos Nacionales S.A Company.

\section{CONSENT FOR PUBLICATION}

Not applicable.

\section{CONFLICT OF INTEREST}

The authors declare no conflict of interest, financial or otherwise.

\section{ACKNOWLEDGEMENTS}

The authors wish to thank the Reactivos Nacionales S.A Company for the financial support as well as for making available the infrastructure for experimental development in their facilities and for their decision to solve the problem with the $\mathrm{H}_{2} \mathrm{~S}$ that was finally achieved.

\section{REFERENCES}

[1] D. Polhemus, and D. Jefer, Emergence of Hydrogen Sulfide as an Endogenous Gaseous Signaling Molecule in Cardiovascular Disease., American Heart Association, Inc., 2014, pp. 730-737.

[2] CEPA, Draft Screening Assessment Hydrogen Sulfide (H2S), Sodium Sulfide (NaHS) and Sodium Sulfide Na2S, CAS RN 7783., American Chemical Society: Canada, 2017.

[3] J. Jiang, A. Chan, S. Ali, A. Saha, K. Haushalter, M. Wai, M. Glasheen, J. Parker, M. Brenner, S. Mahon, H. Patel, R. Ambasudhan, S. Lipton, R. Pilz, and G. Boss, "Hydrogen Sulfide-Mechanisms of Toxicity and Development of an Antidote", Sci. Rep., vol. 6, pp. 1-10, 2016.

[http://dx.doi.org/10.1038/srep20831]

[4] M.G. Costigan, "Hydrogen sulfide: UK occupational exposure limits", Occup. Environ. Med., vol. 60, no. 4, pp. 308-312, 2003. [http://dx.doi.org/10.1136/oem.60.4.308] [PMID: 12660382]

[5] NIH, Hidrogen sulfide, 2018.

[6] M. Amosa, I. Mohammed, and S. Yaro, "Sulphide Scavengers in oil and gas industry - A Review", NAFTA, vol. 61, no. 2, pp. 85-92, 2010.

[7] R. Henao, Riesgos Quimicos., Ecoe Ediciones: Madrid, España, 2010.

[8] T.L. Guidotti, "Hydrogen sulfide: advances in understanding human toxicity", Int. J. Toxicol., vol. 29, no. 6, pp. 569-581, 2010. [http://dx.doi.org/10.1177/1091581810384882] [PMID: 21076123]

[9] ATSDR, Hydrogen Sulfide (H 2 S) CAS 7783-060-4; UN 1053, 2014.

[10] R. Steudel, "Mechanism for the Formation of Elemental Sulfur from Aqueous Sulfide in Chemical and Microbiological Desulfurization Processes", Ind. Eng. Chem. Res., pp. 1417-1423, 1996. [http://dx.doi.org/10.1021/ie950558t]

[11] Y. Gendel, N. Levi, and O. Lahav, H2S(g) Removal using a Modified, Low-pH Liquid Redox Sulfur Recovery (LRSR) Process with Electrochemical Regeneration of the Fe catalyst Couple, 2009. [http://dx.doi.org/10.1021/es901594j]

[12] Z. Guo, T. Zhang, T. Liu, J. Du, B. Jia, S. Gao, and J. Yu, "Nonaqueous System of Iron-Based Ionic Liquid and DMF for the Oxidation of Hydrogen Sulfide and Regeneration by Electrolysis", Environ. Sci. Technol., vol. 49, no. 9, pp. 5697-5703, 2015. [http://dx.doi.org/10.1021/es505728f] [PMID: 25822982]

[13] H. Maat, J. Hogendoorn, and G. Versteeg, "The removal of hydrogen sulfide from gas streams using an aqueous metal sulfate absorbent Part I The absorption of hydrogen sulfide in metal sulfate solutions", Separ. Purif. Tech., pp. 183-197, 2005 a. 
[14] H. Maat, J. Hogendoorn, and G. Versteeg, "The removal of hydrogen sulfide from gas streams using an aqueous metal sulfate absorbent Part II. The regeneration of cooper sulfide to cooper oxide - an experimental study", Separ. Purif. Tech., pp. 199-213, 2005. b

[15] A. Gupta, S. Ibrahim, and A. Al Shoaibi, "Advance in sulfur chemistry for treatment of acid gases", Pror. Energy Combust. Sci., pp. 65-92, 2016.

[http://dx.doi.org/10.1016/j.pecs.2015.11.001]

[16] A. Wiheeb, I. Shamsudin, M. Ahmad, M. Murat, J. Kim, and M. Othman, "Present technologies for hydrogen sulfide removal from gaseous mixtures", Rev. Chem. Eng., pp. 449-470, 2013.

[http://dx.doi.org/10.1515/revce-2013-0017]

[17] K. McIntush, D. Mamrosh, K. Fisher, and C. Beitler, "Caustic Scrubber Design for Refinery Fuel Gas, Sour Water Stripper Gas, and Other Refinery Applications", Brimstone Sulfur Symposium, 2012 Vail - Colorado

[18] C. Ulloa, Declaración de Impacto Ambiental "Aumento de Capacidad de Producción de Planta Productora de Sulfhidrato de Sodio., Centro de Ciencias Ambientales EULA-Chile: Concepción, Chile, 2007.

[19] J. Manganaro, Production of sodium hydrosulfide, U.S. Patent and Trademark Office: Washington, D.C, 1984.

[20] D. Mamrosh, K. McIntush, and K. Fisher, "Caustic Scrubber Designs for H2S Removal from Refinery Gas Streams", The 2014 AFPM Annual Meeting AM-14, 2014

[21] D. Mamrosh, C. Beitler, and K. Fisher, Consider improved scrubbing designs for acids gases Better application of process chemistry enables efficient sulfur abatement., Hidrocarbon Proccesing, 2008, pp. 69-74.

[22] K. Se, S. Kumar, Y. Jamal, and P. Hung, "Optimization of Sodium Hydrosulfide Synthesis for Metal Recovery from Wastewater Using Flue Gas Containing", J. Environ. Eng., vol. 142, no. 9, 2016.

[23] M. Shahrak, E. Ebrahimzadeh, and F. Shahraki, "Removal of Hydrogen Sulfide from Hydrocarbon Liquids using a caustic solution", Energy Source, part A: Recovery, Utilization, and Environmental effects, vol. 37:8, pp. 791-798, 2015 .

[http://dx.doi.org/10.1080/15567036.2011.584121]

[24] M. Roelands, R. Cuypers, K. Kruit, H. Oversloot, J. Ard, W. Duvalois, L. van Vliet, and C. Hoegaerts, "Preparation \& characterization of sodium sulfide hydrates for application in thermochemical storage systems", Energy Procedia, pp. 257-266, 2015.

[http://dx.doi.org/10.1016/j.egypro.2015.02.122]

[25] R. de Boer, W. Haije, and J. Veldhuis, "Determination of structural, thermodynamic and phase properties in the Na2S-H2O system for application in a chemical heat pump", Thermochim. Acta, pp. 3-19, 2003.

[26] L. Border, W. River, and E. Gerhart, "Production of concentrated sodium hydrosulphide solutions", Patent No. 2346550

[27] J. Andersson, and M. Azoulay, "Mechanisms and Kinetics of the thermal decomposition of sodium sulphide pentahydrate under controlled water vapour pressure", J. Chem. Soc., Dalton Trans., pp. 469-475, 1986.

[http://dx.doi.org/10.1039/dt9860000469]

[28] F. Trausel, A. de Jong, and R. Cuypers, "A review on the properties of salt hydrates for thermochemical storage", Energy Procedia, pp. 447-452, 2014.

[http://dx.doi.org/10.1016/j.egypro.2014.02.053]

[29] Q. Li, and J.R. Lancaster Jr, "Chemical foundations of hydrogen sulfide biology", Nitric Oxide, vol. 35, pp. 21-34, 2013. [http://dx.doi.org/10.1016/j.niox.2013.07.001] [PMID: 23850631]

[30] V. Bontozoglou, and A. Karabelas, "Simultaneous absorption of H2S and $\mathrm{CO} 2$ in $\mathrm{NaOH}$ Solutions: Experimental and numerical study of the performance of a short-time contactor", Ind. Eng. Chem. Res., vol. 32, pp. $165-172,1993$

[http://dx.doi.org/10.1021/ie00013a022]

[31] H. Maat, M. A1, J. Hogendoorn, J. Niederer, and G. Versteeg, "Theoretical and Experimental Study of the Absorption rate of H2S in CuSO4 Solutions: The Effect of Enhancement of Mass Transfer by a Precipitation Reaction", Chem. Eng. Res. Des., pp. 100-108, 2007. [http://dx.doi.org/10.1205/cherd06110]

[32] C. Jia, and W. Lu, "Simultaneous sulfur dioxide absorption and hydrogen sulfide generation in an aqueous solution of sodium sulfide", Environ. Sci. Technol., pp. 377-384, 1996.

[http://dx.doi.org/10.1021/es940691x]

[33] R.J. Reiffenstein, W.C. Hulbert, and S.H. Roth, "Toxicology of hydrogen sulfide", Annu. Rev. Pharmacol. Toxicol., vol. 32, pp. 109-134, 1992.

[http://dx.doi.org/10.1146/annurev.pa.32.040192.000545] [PMID:
1605565]

[34] A. Lewis, "Review of metal sulphide precipitation", Hydrometallurgy, vol. 104 , pp. 222-234, 2010.

[http://dx.doi.org/10.1016/j.hydromet.2010.06.010]

[35] D. Gaspar, "Some remarks on the presence of metallic sulphurs in aggregates", Mater. Constr., vol. 25, no. 159, pp. 29-42, 1975. [http://dx.doi.org/10.3989/mc.1975.v25.i159.1259]

[36] "Die Acidität des hydrogensulfidions HS-", Helv. Chim. Acta, vol. 47, no. 1, pp. 266-271, 1964

[http://dx.doi.org/10.1002/hlca.19640470135]

[37] R. Petrucci, and P.J. Moews, "H2S Equilibria; the precipitation and solubilities of metal sulfides", J. Chem. Educ., pp. 391-394, 1962. [http://dx.doi.org/10.1021/ed039p391]

38] P. Ricca, A study in the oxidation of kraft black liquor., Florida, 1962.

[39] M. Al, A. Heesink, and G. Versteeg, "Precipitation of metal sulphides using gaseous hydrogen sulphide: mathematical modelling", Chem. Eng. Sci., pp. 567-579, 2004.

[40] F. Herr, and G. Helz, "Measurement of activity coefficient of aqueous $\mathrm{NaSH}$ to $80^{\circ}$ and $0.2 \mathrm{~m}$ in the system NaSH-H2S-H2O", J. Solution Chem., pp. 833-852, 1976.

[http://dx.doi.org/10.1007/BF01167238]

[41] V. Pangarkar, Design of Multiphase Reactors., John Wiley \& Sons, Inc: Hoboken, New Jersey, 2015.

[42] S. Asiri, Design and Implementation of Differential Agitators to Maximize Agitating Performance, 2012.

[http://dx.doi.org/10.5923/j.mechanics.20120206.01]

[43] I. Torotwa, and C. Ji, A Study of the Mixing Performance of Different Impeller Designs in Stirred Vessels Using Computational Fluid Dynamics., Designs, 2018, pp. 1-16.

[44] G. Tatterson, Fluid Mixing and Gas Dispersion in Agitated Tanks., McGraw-Hill: New York, NY, USA, 1991.

[45] A. Stankiewicz, "MULTIPHASE REACTORS," in CHEMICAL ENGINEERING AND CHEMICAL PROCESS TECHNOLOGY., vol. Vol. III. Eolss Publishers Co. Ltd: United Kingdom, 2010, pp. 90-121.

[46] P. Trambouze, H. Van Landeghem, and J. Wauquier, Chemical Reactors design/engineering/operation., Gulf Publishing Company: Houston, 1988 .

[47] W. McCabe, J. Smith, and P. Harriot, Unit Operations of Chemical Engineering., 7th ed McGraw Hill Higher Education: New York, 2005.

[48] E. Paul, V. Atiemo, and S. Kresta, Handbook of Industrial Mixing Science and Practice., A John Wiley \& Sons, INC.: Hoboken, New Jersey, 2004.

[49] K. NG, N. Fentiman, K. Lee and M. Yianneski, "Assessment of Sliding mesh CFD Predictions and LDA Measurements of the Flow in a Tank Stirred by Rusthon Impeller", Institution of Chemical Enginners, pp. 737-747, 1998.

[50] J. Ducoste, and M. Clark, "The Influence of Tank Size and Impeller Geometry on Turbulent Flocculation: I. Experimental", Environ. Eng. Sci., pp. 215-224, 1998.

[http://dx.doi.org/10.1089/ees.1998.15.215]

[51] L. Lipowska, "The influence of geometric parameters on the ideal mixing range of liquid in a continuous flow stirred tank reactor", Chem. Eng. Sci., pp. 1901-1908, 1974.

[http://dx.doi.org/10.1016/0009-2509(74)85007-4]

[52] M. Bouaifi, G. Hebrard, D. Bastoul, and M. Roustan, A comparative study of gas hold-up, bubble size, interfacial area and mass transfer coefficients in stirred gas-liquid reactors and bubble columns. Chemical Engineering and Processing - Process Intensification, 2001, pp. 97-111.

[53] J. Ard, L. van Vlieta, C. Hoegaerts, M. Roelands, and R. Cuypers, "Thermochemical heat storage - from reaction storage density to system storage density", Energy Procedia, pp. 128-137, 2016.

[54] M. Senouci, F. Kies, and F. Bentahar, "Hydrodynamics and Bubble Size Distribution in a Stirred Reactor", Arab. J. Sci. Eng., pp. 5905-5917, 2018 [http://dx.doi.org/10.1007/s13369-018-3071-z]

[55] J. Middleton, and J. Smith, Gas-Liquid Mixing in Turbulent SystemsHandbook of Industrial Mixing Science and Practice, A John Wiley \& Sons, INC.: Hoboken, New Jersey, 2004, pp. 585-585.

[56] P. Moilanen, M. Laakkonen, and J. Aittamaa, "Modeling aerated fermenters with computational fluid dynamics", Ind. Eng. Chem. Res., pp. 8656-8663, 2006. [http://dx.doi.org/10.1021/ie060097j]

[57] Q. Yan, X. Zhang, and L. Zhang, "Chapter 13. Analysis and Optimization on Solar Energy Chemical Heat Storage Material", Proceedings of the 8th International Symposium on Heating, 
Ventilation and Air Conditioning, vol. Volume 2, 2014pp. 121-130 [http://dx.doi.org/10.1007/978-3-642-39581-9_13]

[58] K. Maeda, "European Patent Application", Patent 0300859 A2, 25.01.89 Bulletin $89 / 04$

[59] J. Zhang, Z. Gao, Y. Cai, H. Cao, Z. Cai, and Y. Bao, "Power consumption and mass transfer in a gas-liquid-solid stirred tank reactor with various triple-impeller combinations", Chem. Eng. Sci., pp. 464-475, 2017.

[http://dx.doi.org/10.1016/j.ces.2017.02.002]

[60] S. Banisi, J. Finch, A. Laplante, and M. Weber, "EFFECT OF SOLID PARTICLES ON GAS HOLDUP IN FLOTATION COLUMNS--I. MEASUREMEN", Chem. Eng. Sci., pp. 2329-2334, 1995. [http://dx.doi.org/10.1016/0009-2509(95)00075-G]

[61] N. Hidaka, M. Ontitani, T. Matsumato, and S. Morooka, "Axial mixing segregation of multicomponent coarse particles fluidized by concurrent gas-liquid flow", Chem. Eng. Sci., pp. 3427-3434, 1992. [http://dx.doi.org/10.1016/0009-2509(92)85054-F]

[62] Y. Bao, Z. Hao, Z. Gao, L. Shi, J. Smith, and R. Thorpe, "Gas dispersion and solid suspension in a three-phase stirred tank with multiple impellers", Chem. Eng. Commun., pp. 801-825, 2006. [http://dx.doi.org/10.1080/00986440500267261]

[63] N. Dohi, T. Takahashi, K. Minekawa, and Y. Kawase, "Power consumption and solid suspension performance of large-scale impellers in gas-liquid-solid threephase stirred tank reactors", Chem. Eng. J., pp. 103-114, 2004.

[http://dx.doi.org/10.1016/S1385-8947(03)00148-7]

[64] H. Rashid, N. Hasan, and M. Mohamad, Temperature Peak Analysis and Its Effect on Absorption Column for CO2 Capture Process at Different Operating Conditions., Chemical Product and Process Modeling, 2014, pp. 105-115.

[65] M. Suleimenov, and R. Krupp, "Solubility of hydrogen sulfide in pure water and in $\mathrm{NaCl}$ solutions, from 20 to $320^{\circ} \mathrm{C}$ and at saturation pressures", Geochim. Cosmochim. Acta, pp. 2433-2444, 1994. [http://dx.doi.org/10.1016/0016-7037(94)90022-1]

[66] A. Nienow, "Stirring and Stirred-Tank Reactors", Chemieingenieurtechnik (Weinh.), vol. 86, no. 12, pp. 1-13, 2014. [http://dx.doi.org/10.1002/cite.201400087]

[67] S. Narayanan, V. Bhatia, D. Guha, and M. Rao, "Suspension of solids by mechanical agitation", Chem. Eng. Sci., pp. 223-230, 1969. [http://dx.doi.org/10.1016/0009-2509(69)80031-X]

[68] D. García, and U. Jáuregui, "Hidrodinámica en tanques agitados con turbinas de disco con paletas planas", Rev. Fac. Ing., pp. 97-113, 2006.

[69] C. Wong, J. Wang, and S. Huang, "Investigation of Fluid Dynamics in Mechanically Stirred aerated Slurry Reactors", Can. J. Chem. Eng., pp. 412-419, 1987.

[http://dx.doi.org/10.1002/cjce.5450650308]

[70] E. Molina, F. Camacho, F. Valdes, and L. Lorenzo, "Determination of interfacial-areas in stirred tanks - influence of the tank geometry and sparger arrangement", Afinidad, vol. XLVII, pp. 13-18, 1990.

[71] T. Zwietering, "Suspending of solid particles in liquid by agitators", Chem. Eng. Sci., pp. 244-253, 1958.

[http://dx.doi.org/10.1016/0009-2509(58)85031-9]

[72] I. Ayranci, and M. Kresta, "Critical analysis of Zwietering correlation for solids suspension in stirred tanks", Chem. Eng. Res. Des., pp.
413-422, 2014.

[http://dx.doi.org/10.1016/j.cherd.2013.09.005]

[73] R. Jafari, P. Tanguy, and J. Chaouki, "Characterization of Minimum Impeller Speed for Suspension of Solids in Liquid at High Solid Concentration,Using Gamma-Ray Densitometry", Int. J. Chem. Eng., pp. 1-15, 2012.

[http://dx.doi.org/10.1155/2012/945314]

[74] G. Kasat, and A. Pandit, "Review on mixing characteristics in solidliquid and solid-liquid-gas reactor vessels", Can. J. Chem. Eng., pp. 618-643, 2005 .

[http://dx.doi.org/10.1002/cjce.5450830403]

[75] W. Bujalski, K. Takenaka, S. Paolini, M. Jahoda, A. Paglianti, A. Takahashi, A. Nienow, and A. Etchells, "Suspensions and Liquid Homogenization in high solids concentration stirred chemical reactors", Chem. Eng. Res. Des., pp. 241-247, 1999. [http://dx.doi.org/10.1205/026387699526151]

[76] M. Kraume, "Mixing Time in Stirred Suspensions", Chem. Eng. Technol., pp. 313-318, 1992. [http://dx.doi.org/10.1002/ceat.270150505]

[77] P. Armenante, E. Nagamine, and J. Susanto, "Determination of Correlations to Predict the minimum Agitation Speed for Complete Solid Suspension in Agitated Vessels", Can. J. Chem. Eng., pp. 413-419, 1998.

[http://dx.doi.org/10.1002/cjce.5450760310]

[78] K. Saravanan, A. Patwardhan, and J. Joshi, "Critical impeller speed for solid suspension in gas inducing type mechanically agitated contactors", Can. J. Chem. Eng., pp. 664-676, 1997. [http://dx.doi.org/10.1002/cjce.5450750403]

[79] R. Brown, P. Jones, and J. Middleton, "Experimetal Methods. Part A: Measuring Tools and Techniques for Mixing and Flow Visualization Studies-Solid Liquid Mixing," in Handbook of Industrial Mixing., Jhon Wiley \&Sons: Hoboken, 2004, pp. 177-182.

[80] S. Ibrahim, and A. Nienow, Particle suspension in the turbulent regime: the effect of impeller type and impeller/vessel configuration, 1996.

[81] Y. Selima, Y. Fangary, and N. Mahmoud, "Determination o minimum speed requeried for solid suspension in stirred vessels using pressure measurements", Can. J. Chem. Eng., pp. 661-666, 2008. [http://dx.doi.org/10.1002/cjce.20037]

[82] Y. Zhu, and J. Wu, "Critical impeller speed for suspending solids in aerated agitation tanks", Can. J. Chem. Eng., pp. 1-6, 2002. [http://dx.doi.org/10.1002/cjce.5450800417]

[83] C. Chapman, A. Nienow, M. Cooke, and J. Middleton, "Particle-GasLiquid Mixing in Stirred Vessels. Part I Particle-Liquid Mixing", Chem. Eng. Res. Des., pp. 71-81, 1983.

[84] J. Hofmeester, "Gas hold-up measurements in bioreactors", Trends Biotechnol., pp. 19-22, 1988.

[http://dx.doi.org/10.1016/0167-7799(88)90109-6]

[85] R. Bates, P. Fondy, and R. Corpstein, "Examination of Some Geometric Parameters of Impeller Power", Ind. Eng. Chem. Process Des. Dev., pp. 310-314, 1963. [http://dx.doi.org/10.1021/i260008a011]

[86] Aerstin. and G. Street, Applied Chemical Process Design,Fourth Printing, New York., Plenum Press: London, 1989.

C) 2019 Reátegui-Romero et al.

This is an open access article distributed under the terms of the Creative Commons Attribution 4.0 International Public License (CC-BY 4.0), a copy of which is available at: https://creativecommons.org/licenses/by/4.0/legalcode. This license permits unrestricted use, distribution, and reproduction in any medium, provided the original author and source are credited. 